\title{
CUPINS (INSECTA: ISOPTERA) EM PLANTIOS DE EUCALYPTUS SPP. (MYRTACEAE) NA ESTAÇÃO EXPERIMENTAL DE CIÊNCIAS FLORESTAIS DA UNIVERSIDADE DE SÃO PAULO, NO MUNICÍPIO DE ANHEMBI, SÃO PAULO
}

\section{LUCIANE KERN JUNQUEIRA \\ Bióloga}

Orientador: Prof. Dr. EVÔNEO BERTI FILHO

Dissertação apresentada à Escola
Superior de Agricultura "Luiz de Queiroz",
Universidade de São Paulo, para
obtenção do Título de Mestre em
Ciências, Área de Concentração:
Ciências Florestais.

\section{PIRACICABA}

Estado de São Paulo - Brasil

Dezembro - 1999 


\title{
Dados Internacionais de Catalogação na Publicação (CIP) DIVISÃo DE BIBLIOTECA E DOCUMENTAÇÃO - Campus "Luiz de Queiroz"/USP
}

\author{
Junqueira, Luciane Kern \\ Cupins (Insecta: Isoptera) em plantios de Eucalyptus spp. (Myrtaceae) na Estação \\ Experimental de Ciências Florestais da Universidade de São Paulo, no município de \\ Anhembi, São Paulo. / Luciane Kern Junqueira. - Piracicaba, 1999. \\ 57 p. : il \\ Dissertação (mestrado) - - Escola Superior de Agricultura Luiz de Queiroz, 1999. \\ Bibilografia \\ 1. Cupim 2. Eucalipto 4. Inseto 5. Isoptero I.Título
}

CDD 634.96736 


\section{AGRADECIMENTOS}

- A Deus, que traça nossa trajetória nesta vida, mas que sempre nos dá a oportunidade de escolha, obrigada por me iluminar na decisão certa.

- À minha familia, obrigada pelo incentivo e por acreditarem que eu poderia ir um pouco mais longe, não negando esforços para que isto acontecesse. Todas as conquistas são devidas a educação e as oportunidades que vocês me deram.

- André, nas dificuldades sempre crescemos juntos e neste momento só uma palavra pode resumir o que nos une: amor. Obrigada por estar ao meu lado, pelo amor, carinho, apoio e ajuda em todos os momentos.

- À Elena, amizade e presença constante, a ti devo o entusiasmo pela biologia.

- À $D^{a}$ Bete e Tia Lena, obrigada por serem a minha segunda família, tornado a casa de vocês parte da minha.

- Às amigas, separadas pela distância, mas não no coração: Alemoa, Emília, Eunice, Gláucia, Júlia, Letícia, Lisiane e Simoninha. Obrigada pela amizade e palavras de conforto em todos os momentos difíceis.

- Às novas amigas: Ranyse, Mônica, Sandra, Adriana e Marcinha, obrigada por fazerem parte da minha vida de agora em diante. 
- Ao prof. Dr. Evôneo Berti Filho, obrigada pelos conhecimentos transmitidos, pela paciência em corrigir meus erros e, principalmente, por me receber junto ao seu laboratório como sua orientanda.

- Ao Dr. Luiz Roberto Fontes, obrigada pela identificação do material, pelos comentários e correções do trabalho e pelo grande incentivo à continuidade deste projeto.

- Ao prof. Dr. Sérgio Batista Alves e sua equipe de trabalho, em especial a Daniela, obrigada pela ajuda na obtenção e confecção das iscas.

- Ao Rildo e Carlos, obrigada pelo empenho e tempo dedicados na realização deste projeto. Sem o auxílio de vocês seria impossivel ultrapassar as dificuldades do trabalho em campo.

- Aos professores e colegas de Ciências Florestais e de Entomologia, obrigada pelo companheirismo e auxilio durante a elaboração deste trabalho. 


\section{SUMÁRIO}

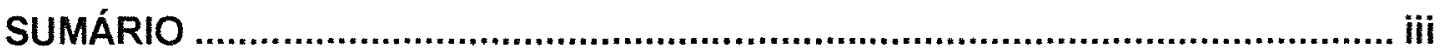

RESUMO

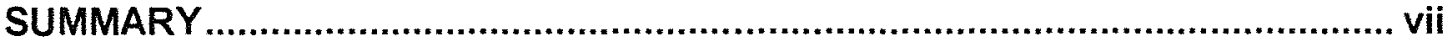

1 INTRODUÇÃO

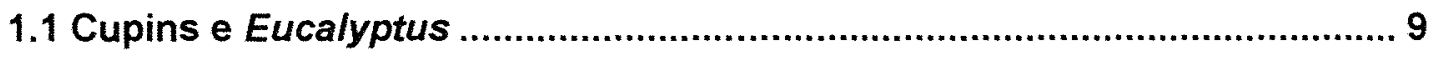

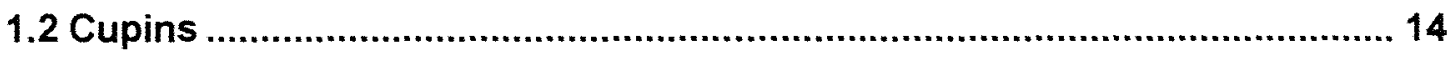

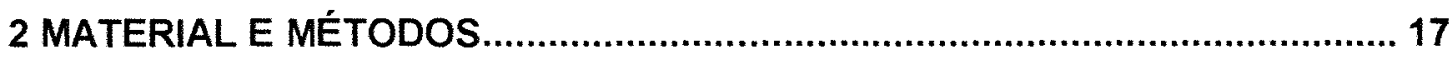

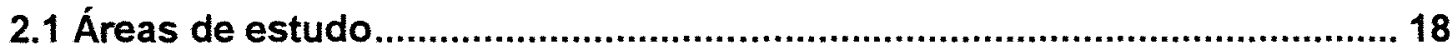

2.2 Levantamento de mudas atacadas por cupins........................................... 22

2.3 Coleta de cupins com iscas Termitrap ${ }^{\circledR}$....................................................... 22

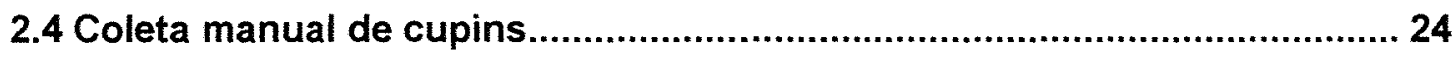

2.5 Georeferenciamento das áreas de estudo ............................................... 27

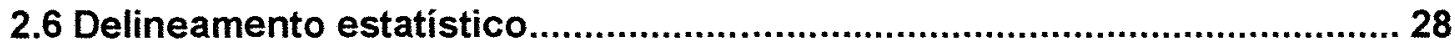

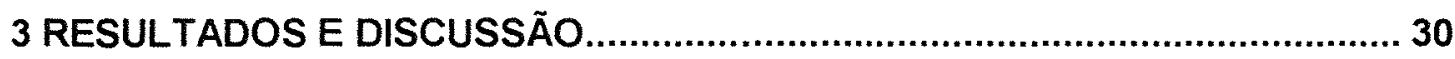

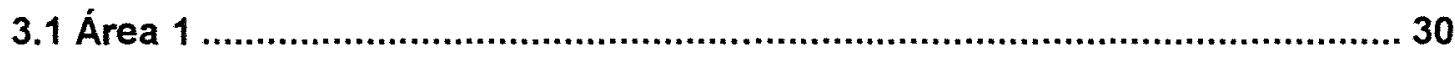

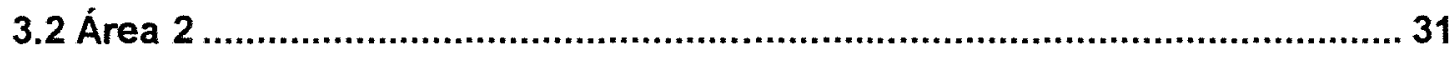

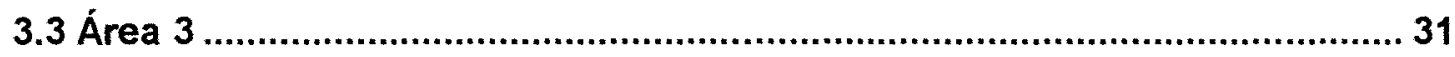

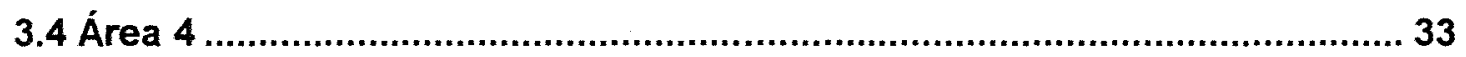

3.5 Georeferenciamento das áreas de estudo …............................................ 35

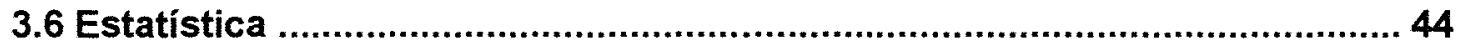

4 CONCLUSÕES

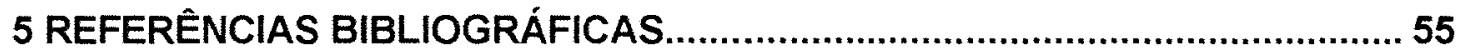




\section{CUPINS (INSECTA: ISOPTERA) EM PLANTIOS DE EUCALYPTUS SPP. (MYRTACEAE) NA ESTAÇÃO EXPERIMENTAL DE CIÊNCIAS FLORESTAIS DA UNIVERSIDADE DE SÃO PAULO, NO MUNICÍPIO DE ANHEMBI, SÃO PAULO}

Autora: LUCIANE KERN JUNQUEIRA Orientador: Prof. EVÔNEO BERTI FILHO

\section{RESUMO}

Este trabalho teve por objetivo realizar levantamento das espécies de cupins presentes em quatro áreas de cultivo de Eucalyptus na Estação Experimental de Ciências Florestais de Anhembi (SP), ESALQ/USP. Para tanto, foram contadas as mudas atacadas por cupins nas áreas 1,2 e 4, e utilizadas iscas Termitrap para a coleta de cupins subterrâneos nas quatro áreas de estudo. Na Área 3 foram amostrados manualmente individuos dos ninhos de montículo e sob a casca das árvores, utilizando a metodologia de linhas de transectos. Sistema de GPS, foi utilizado para mapear os locais com cupins e as áreas. Os cupins coletados foram armazenados no Laboratório de Entomologia Florestal, ESALQ/USP e identificados pelo Dr. Luiz Roberto Fontes. $\mathrm{Na}$ área 1 (E. saligna), com $11,08 \%$ de mudas mortas e $4,29 \%$ de iscas com cupins, foram coletados Embiratermes sp.; Comitermes sp. e Heterotermes tenuis. $\mathrm{Na}$ área 2 ( $E$. urophylla $\times E$. grandis) $9,15 \%$ das mudas morreram e 2,09\% das iscas apresentaram cupins, sendo coletados individuos da subfamília Apicotermitinae, C. cumulans e $H$. tenuis. $\mathrm{Na}$ área 3 (E. pilularis), foram coletados manualmente Cornitermes sp., C. bequaerti, C. cumulans, Diversitermes diversimilis e $H$. tenuis e, 
nas iscas, Araujotermes sp., $D$. diversimilis e $H$. tenuis. A área 4 ( $E$. urophylla), com tratamento químico das mudas (deltametrina), não apresentou mudas mortas, porém ocorreram cupins em $3,11 \%$ das iscas, sendo coletados Cornitermes sp., C. cumulans e $H$. tenuis. Sugere-se que as iscas de papelão não têm a mesma eficiência que se verifica nas áreas agrícolas, porque nos solos de reflorestamento ocorrem raízes, cascas, restos de madeiras, etc, que são mais atrativos para os cupins. 
TERMITES (INSECTA: ISOPTERA) OCCURRING IN EUCALYPTUS SPP. PLANTATIONS IN THE FOREST EXPERIMENTAL STATION OF THE UNIVERSITY OF SÃO PAULO, IN ANHEMBI, STATE OF SÃO PAULO, BRAZIL

Author: LUCIANE KERN JUNQUEIRA Adviser: Prof. EVÔNEO BERTI FILHO

\section{SUMMARY}

This research deals with a survey of the termite species occurring in four areas of an Eucalyptus plantation in the Forest Experimental Station of University of São Paulo, Brazil. Seedlings attacked by termites in the areas 1,2 and 4 were counted while Termitrap ${ }^{\oplus}$ baits were used to collect subterranean in four areas selected. In the area 3 termites were manualy sampled from mound colonies and under the bark of the trees, by using transect line methodology. GPS (Global Positional System) was used to map the areas and the sites with termites. The termites collected were stored at the Laboratory of Forest Entomology ("Escola Superior de Agricultura Luiz de Queiroz" University of São Paulo) and later identified by Dr. Luiz Roberto Fontes. The results were as follows: Area 1 ( $E$. saligna) $-11,08 \%$ of dead seedlings and $4,29 \%$ of baits with termites species Embiratermes sp., Cornitermes sp. and Heterotermes tenuis; Area 2 (E. urophylla $\times E$. grandis) $-9,15 \%$ of dead seedlings and $2,09 \%$ of baits with no identified species of the subfamily Apicotermitinae, $C$. cumulans and $H$. tenuis; Area 3 (E. pilularis) - manually collected the species Comitermes sp., C. bequaerti, $C$. cumulans, Diversitermes diversimilis and $H$. tenuis, and collected by the baits the 
species Araujotermes sp., $D$. diversimilis and $H$. tenuis; Area 4 ( $E$. urophylla) - no dead seedlings were found (seedling root system treated with deltametrin), but in $3,11 \%$ of the baits there were collected the species Comitermes sp., C. cumulans and $\mathrm{H}$. tenuis. The data suggest that the efficiency of the baits (Termitrap ${ }^{\circledR}$ ) to survey termites in a forest area is lower than that observed in agricultural area, maybe due to the high amount of wooden residues present in the forest soil. 


\section{INTRODUÇÃO}

\subsection{Cupins e Eucalyptus}

Apesar da importância da madeira como fonte energética nos paises desenvolvidos, interesses em remediar os problemas do aumento da demanda, e possivel escassez, têm origem recente. A solução surgiu com a introdução de espécies exóticas, de crescimento rápido, como as do gênero Eucalyptus. Na prática, características edáficas, climáticas e demográficas impuseram severas limitações neste tipo de cultivo. Estas pressões ocasionaram perda no estoque do viveiro e das plantas jovens, principalmente devido ao ataque por cupins (Wardell, 1987).

Quando se consideram florestas naturais, os cupins atuam como insetos benéficos, participando na decomposição de matéria orgânica, ciclagem de nutrientes, aeração e drenagem de solos, além de atuar no estabelecimento de novos solos em áreas erodidas (Berti Filho, 1995). Porém, nas florestas tropicais que utilizam espécies exóticas, o cupim provoca danos tão significativos, que pode ser considerado um fator limitante para a implantação de florestas comerciais (Harris, 1971; Cowie et al., 1989).

$\mathrm{Na}$ preparação do solo para o plantio de eucaliptos, a vegetação é completamente retirada e não há acúmulo de "litter", pelo menos no primeiro ano, privando os cupins de sua alimentação normal. Estes, na busca de fontes alternativas de alimento, acabam por atacar o eucalipto (Nair \& Varma, 1985).

$\mathrm{Na}$ América do Sul, Índia e savanas da África, o gênero Eucalyptus é muito suscetivel ao ataque dos cupins (Coaton, 1957; Harris, 1966), que pode ocorrer desde as mudas até árvores adultas, de diferentes maneiras (Selander \& Budala, 1983).

Para Wardell (1987), os cupins são uma das principais pragas da silvicultura nos trópicos, provocando perdas econômicas substanciais nos viveiros e durante 0 
estabelecimento de plantações. As espécies de Eucalyptus são particularmente suscetiveis, além de outros gêneros exóticos como Cupressus, Pinus, Callitris e Casuarina, que também podem ser atacados. Atualmente, há crescente interesse na busca de métodos alternativos para seu controle devido, principalmente, as restrições ao uso de inseticidas.

Segundo Wardell (1987), muitas das questões referentes ao problema com cupins em cultivos de Eucalyptus permanecem sem resposta. Há necessidade urgente de programas de pesquisa, que estudem as relações ecológicas entre cupins e árvores hospedeiras e possiveis correlações com fatores edáficos. Nair \& Varma (1985) sugerem que mais fatores estejam relacionados na interação eucalipto $x$ cupins, tais como espécies de cupins presentes, densidade populacional, ritmo sazonal de atividade, acúmulo de "litter" e madeira, condições do solo, estado fisiológico da planta, idade, estado de estabelecimento e espécies em questão.

Os cupins-praga de florestas implantadas podem ser divididos em dois grupos (Wilcken \& Raetano, 1995):

a) os cupins que atacam mudas, desde o plantio até a idade de um ano, chamados cupins das mudas, raizes ou cupins de solo: Ex.: Syntermes molestus, S. insidians, Cornitermes cumulans, etc., que ocasionam a destruição do sistema radicular ou anelamento da muda na região do colo, danos que geralmente levam a planta à morte. Caso as condições do solo sejam favoráveis, as mudas podem resistir ao ataque, formando calos que irão originar novo sistema radicular acima do destruído, ou ainda emitir brotação para formar nova parte aérea nos casos de anelamento da região do colo. Apesar disso, as árvores não terão sustentação adequada, com sistema radicular deficiente, ou serão árvores dominadas, devido ao atraso do desenvolvimento inicial. A mortalidade nestes casos é expressiva, ocasionando danos que, em mudas de Eucalyptus grandis no Brasil, chegaram a $18 \%$, devido ao ataque de Cornitermes sp. (Wilcken, 1992). Para plantios comerciais, a porcentagem de falhas aceitável é de 2 a $5 \%$, acima deste, o replantio torna-se oneroso; 
b) os cupins que atacam árvores formadas, com mais de dois anos, destruindo seu interior, denominados cupins de cerne ou da casca: Ex: Coptotermes testaceus. O cupim penetra pela raiz, construindo galerias no interior do tronco, destruindo o cerne e deixando as árvores ocas. Como o ataque começa pelas raízes, a brotação dos tocos também é prejudicada, causando falhas no "stand" e queda da produtividade. São cupins de difícil detecção em campo, pois não há sintomas aparentes de danos internos, só evidenciados durante o corte ou a colheita da madeira.

Nair \& Varma (1985) estudaram a natureza dos danos causados por cupins e os fatores que influenciaram a incidência do ataque para Eucalyptus tereticornis e E. grandis em Kerala, Índia. Foi verificado que os cupins realizam três tipos de ataques: ataque primário, que prejudica o vigor e o crescimento da árvore nova; ataque secundário em árvores mortas por outros agentes $e$, por último, 0 ataque complementar, no qual a morte da árvore resulta de efeitos combinados entre danos causados por cupins e outros fatores.

Em trabalho envolvendo a problemática dos cupins no estabelecimento de plantações de Eucalyptus na África, Wardell (1987) constatou que danos localizados, devido ao ataque por cupins, resultaram em 50-80\% de mortalidade, com período crítico ocorrendo após 4-6 meses do plantio. A grande variedade nas populações de cupins e a atividade sazonal dessas nos sítios acentuaram os prejuizos.

De acordo com Nair \& Varma (1985), na Índia, as espécies de eucaliptos suscetíveis a cupins são: Eucalyptus tereticomis, E. grandis, E. citriodora e E. robusta. Para muitas espécies de eucaliptos os cupins não têm sido listados como pragas, mas não há créditos de espécies resistentes ao ataque e a literatura sugere que todas as espécies da Índia e da África são suscetiveis.

Na região Neotropical, as espécies de Eucalyptus apresentam alta mortalidade nos estágios de desenvolvimento inicial em campo, além de danos em árvores vivas e em cepas devido ao ataque por cupins. Segundo Berti Filho (1993) as espécies mais suscetiveis são: Eucalyptus tereticornis, E. grandis, E. citriodora e E. robusta. 
Dietrich (1989) registrou, pela primeira vez em eucalipto, os gêneros de Termitidae: Aparatermes, Cylindrotermes, Embiratermes, Rhyncotermes, Obtusitermes e Subulitermes. De acordo com Berti Filho (1993), no Brasil, os danos em Eucalyptus spp. são causados por espécies das famílias Kalotermitidae, Rhinotermitidae e Termitidae.

Apesar de muitas vezes causar mortalidade da árvore, os cupins de madeira não dependem das árvores de um plantio como única fonte de alimento (Berti Filho, 1995). Entretanto, em plantios, ao contrário das florestas naturais, ocorre justamente a eliminação da cobertura vegetal do solo. Para Pimentel (1961) e Berti Filho (1995) os surtos em plantios de Eucalyptus só ocorrem devido a redução da diversidade da fauna e da flora. De acordo com Nair \& Varma (1985), dentre os fatores que interagem entre si e ocasionam $o$ ataque de cupins em florestas plantadas estão: a espécie de cupim presente no plantio; a densidade populacional desta; o ritmo de atividade estacional; o acúmulo de serapilheira e demais resíduos no solo; tipo de solo; umidade do solo e estado fisiológico da planta (idade e estado de estabelecimento no campo

No pais, os cupins dos gêneros Heterotermes, Cornitermes, Syntermes, Neocapritermes e Procornitermes são importantes pragas das culturas de cana-deaçúcar, arroz, milho, trigo, amendoim, pastagem e Eucalyptus. Sabe-se que os danos provocados ocorrem em focos isolados, mas não há dados sobre distribuição espacial das colônias no campo, carecendo de dados específicos na literatura nacional (Forti \& Andrade, 1995). Desta forma, é importante salientar que, de acordo com os autores, apesar dos cupins serem numerosos e causarem danos expressivos para a pecuária e agricultura e, também, como pragas domésticas, há insuficiência de estudos e literatura na área. Para os autores, a ausência de dados quantitativos em relação as colônias de cupins, é devida a falta de recursos destinados a estudos básicos.

A ausência de metodologia de avaliação adequada pode provocar um julgamento errôneo da magnitude dos danos causados por cupins, como o constatado por Santos et al. (1990) para os cupins de solo, principalmente as espécies Syntermes insidians e $S$. molestus, responsabilizados por todos os danos que ocorriam às mudas de Eucalyptus logo após o plantio no campo. 
Para Wilcken \& Raetano (1995), o problema com cupins de solo em plantios e florestas de eucalipto é sério e pesquisas sobre métodos de controle e alternativas no controle destas pragas precisam ser intensificadas, pesquisas estas que envolvam 0 estudo sobre a distribuição espacial e amostragem das espécies-praga do eucalipto, determinando assim a viabilidade econômica dos métodos de controle empregados.

Apesar de estarem registradas cerca de 200 espécies no Brasil, este número está seguramente subestimado, pois há espécies descritas que não foram registradas no país, além de muitas que não foram descritas ainda. A informação biológica geral, associada ao nome da espécie, auxilia o diagnóstico e controle de infestações, permitindo sugerir correções à literatura sobre espécies registradas como pragas de culturas, que na realidade não o são. A sistemática é, então, de fundamental importância para o exercício adequado do controle (Fontes, 1995).

Para Wilcken \& Raetano (1995), o controle de cupins subterrâneos pode ser realizado através de barreiras subterrâneas (físicas ou químicas) que impedem a chegada dos operários nas plantas e mudas. A utilização de iscas tóxicas, práticas culturais adequadas e controle biológico são propostas recentes. $O$ controle químico de cupins foi realizado durante longo periodo com a aplicação de clorados: aldrin, dieldrin, heptacloro, clordane e lindane. Com estabilidade no solo e longo periodo residual de controle, estes inseticidas foram abolidos devido ao grande impacto ambiental. Atualmente, novos inseticidas e novas técnicas têm sido pesquisados: aplicação total do inseticida no solo; tratamento das covas de plantio; tratamento do substrato; imersão das mudas e aplicação de cupinicidas nos cupinzeiros

Mariconi et al. (1995) citam alguns defensivos agricolas para o controle do cupim de montículo Cornitermes cumulans: abamectina, fipronil, imidaclopride, endossulfan e fosfeto de alumínio. A aplicação desses defensivos é feita introduzindoos no núcleo do ninho através de canal feito com varão de aço.

O controle cultural baseia-se na adoção de práticas culturais adequadas que reduzem o ataque de cupins às mudas de eucalipto: uso de mudas vigorosas; destruição de galerias subterrâneas; cultivo mínimo (redução do preparo do solo) e adubação e calagem (Wilcken \& Raetano, 1995). 
O controle biológico utiliza inimigos naturais, principalmente predadores e patógenos. A predação oportunista ocorre durante a revoada e fundação da colônia pelo ataque a casta dos reprodutores alados. Pássaros, répteis, anfíbios e mamiferos destacam-se entre os predadores vertebrados e aranhas, vespas, besouros, percevejos e formigas entre os invertebrados. Para as demais castas da colônia, as formigas são os predadores mais atuantes (Wilcken \& Raetano, 1995).

O controle por microrganismos tem demonstrado patogenicidade de algumas espécies de fungos, bactérias e virus, porém é dificultado devido as estratégias de comportamento da colônia, que isola os individuos mortos ou infectados. Como as colônias de cupins oferecem condições ideais para o desenvolvimento de patógenos, novos estudos nesta área devem ser realizados na tentativa de obter métodos eficazes de proliferação dos patógenos (Wilcken \& Raetano, 1995; Diehl-Fleig et al., 1995). Atualmente, como método alternativo, estão sendo desenvolvidas iscas atrativas com fungos entomopatogênicos (Alves \& Almeida, 1995).

\subsection{Cupins}

Os cupins, com mais de 2.000 espécies, pertencem a Ordem Isoptera. Nas Américas, excluindo os fósseis, são encontrados 84 gêneros, pertencentes a cinco famílias: Kalotermitidae, com 15 gêneros e 112 espécies; Rhinotermitidae, com oito gêneros e 34 espécies; Serritermitidae, com um gênero e uma espécie; Termitidae, com 58 gêneros e 363 espécies e Termopsidae, com dois gêneros e quatro espécies (Araújo, 1977; Fontes, 1983; Fontes, 1995).

Amplamente distribuidos nas regiões tropicais e temperadas do mundo (Harris, 1966), quando se consideram florestas naturais, os cupins atuam como insetos benéficos, participando na decomposição de matéria orgânica, ciclagem de nutrientes, aeração e drenagem de solos (Berti Filho, 1995).

Os cupins são insetos sociais polimórficos que vivem em colônias, utilizando produtos de origem vegetal (madeira e papel) e animal (couro e lã) para sua alimentação. De acordo com seu hábitat, podem ser divididos em cupins que vivem na madeira e cupins de solo (de montículo, arboricolas e semi-arborícolas). Os ninhos sobre as árvores estão ligados ao solo por túneis, já que os cupins não coletam 
material da árvore onde nidificam. Os que fazem ninho de montículo, apresentam construção de forma típica e altura variável, com o tipo e profundidade de solo influenciando a distribuição das espécies (Berti Filho, 1993; Forti \& Andrade, 1995).

Os cupins de solo causam prejuizos em sementeiras, toletes de cana, na mandioca, tubérculos e raizes, mudas de eucaliptos, café e frutíferas. Já os cupins de montículo e arborícolas, devido a área ocupada pelos ninhos, impedem a formação de pastagens, dificultam tratos culturais, danificam postes e mourões de cercas, abrigando também, animais peçonhentos, tais como cobras e escorpiões (Berti Filho, 1993). Atualmente, introduz-se o conceito de praga estética, em contraposição a praga econômica para os cupins de pastagem do gênero Comitermes (Fernandes et al., 1998).

Segundo Fontes (1995), a sistemática de cupins incorpora características morfológicas externas, morfologia do tubo digestivo do operário, padrão de arquitetura do ninho, características químicas da secreção defensiva dos soldados, particularidades comportamentais relacionadas com padrões morfológicos e hábitos. Assim, o estudo taxonômico não se restringe ao inseto morto, mas requer informações sobre a biologia geral do inseto. A presença de três castas, com grande variabilidade morfológica dificulta em muito a sistemática, pois cada uma tem potencial taxonômico. Os alados, com grande semelhança entre espécies, são produzidos sazonalmente e estarão ausentes em coleções realizadas fora do período de produção. Os soldados formam a casta mais importante para a taxonomia, apesar de muitas vezes apresentar polimorfismo e estar verdadeiramente ausente na maioria dos gêneros da subfamília Apicotermitinae. Os operários são muito semelhantes e caracteres taxonômicos são obtidos através do estudo do tubo digestivo. Finalmente, o ninho fornece um conjunto de caracteres sistemáticos, baseados principalmente no padrão arquitetural e materiais utilizados para a construção.

Cabe ressaltar a importância de, inicialmente, identificar as espécies presentes em cultivos específicos de cada região, já que esta informação é a base para estudos de bioecologia, comportamento e controle. Estes, por sua vez, irão fornecer subsídios para um manejo adequado destes insetos. Para Berti Filho (1995), o estudo da taxonomia e distribuição de espécies de cupins no Brasil é de extrema necessidade, 
pois somente assim poder-se-á conhecer a distribuição das espécies pragas e o potencial de determinadas espécies se tornarem pragas, bem como avaliar a presença de espécies que utilizavam plantas nativas e que agora estão se adaptando às florestas plantadas.

De acordo com Diehl-Fleig et al. (1995), a ausência de especialistas nas áreas de diagnóstico, sistemática, biologia, controle e prevenção de cupins, é um dos maiores problemas enfrentados atualmente. Os autores ainda salientam a urgência do mapeamento das regiões de maior incidência de cupins; a identificação de espécies de cupins de cada área; a determinação da grandeza dos prejuízos causados pelos cupins nos diversos cultivos e na indústria e, finalmente, a adoção de medidas de controle (preventivas e/ou curativas).

Tendo em vista as questões acima apresentadas, este trabalho tem por objetivo realizar levantamento de espécies de cupins presentes em quatro áreas de cultivo de Eucalyptus na Estação Experimental de Anhembi, que pertence ao Departamento de Ciências Florestais, ESALQ/USP e localiza-se no município de Anhembi, São Paulo. 


\section{MATERIAL E MÉTODOS}

A presente pesquisa foi conduzida na Estação Experimental de Ciências Florestais de Anhembi, pertencente à Universidade de São Paulo e sob administração do Departamento de Ciências Florestais da Escola Superior de Agricultura "Luiz de Queiroz" (ESALQ). A Estação localiza-se no municipio de Anhembi - SP, distante 15 $\mathrm{km}$ do perímetro urbano e a $95 \mathrm{~km}$ de Piracicaba. Destina-se exclusivamente ao desenvolvimento de estudos com espécies florestais, nativas ou exóticas, representando um banco de germoplasma. Abrange uma área de aproximadamente 500 ha, à margem esquerda da represa do rio Tietê, remanescentes das terras desapropriadas pelas Centrais Elétricas de São Paulo (CESP).

Caracterização da área:

- Latitude: $22^{\circ} 47^{\prime} S$

- Longitude: $48^{\circ} 09^{\prime} \mathrm{W}$

- Altitude: $500 \mathrm{~m}$

- Relevo: plano a suave ondulado

- Solo: podzólico, arenoso e profundo

- Clima: verões quentes e chuvosos e invernos moderadamente frios e secos.

- A ocorrência de geadas é rara.

- Temperatura média anual: $21,0^{\circ} \mathrm{C}$

- Temperatura média no mês mais frio: $17,1^{\circ} \mathrm{C}$

- Temperatura média no mês mais quente: $23,7^{\circ} \mathrm{C}$

- Precipitação média anual: $1.350 \mathrm{~mm}$

- Déficit hídrico anual: $20 \mathrm{~mm}$ 


\section{1 Áreas de estudo}

Este experimento consistiu em realizar o levantamento de espécies de cupins em quatro áreas de Eucalyptus (Figura 1). Para tal, foram feitas coletas através de isca Termitrap ${ }^{\circledR}$ nas quatro áreas, e na área 3 também foram feitas coletas manualmente em ninhos de montículo e árvores. As coletas em todas as áreas, ocorreram sempre no periodo diurno entre $8 \mathrm{~h}$ e $13 \mathrm{~h}$, canceladas em caso de chuva, no período de setembro de 1998 a setembro de 1999 .

Paralelamente, foi observado o número de mudas mortas devido a cupins nas áreas 1,2 e 4.

As áreas estudadas foram:

1. Área 1: com $34.600 \mathrm{~m}^{2}$ e 5.922 mudas de Eucalyptus saligna, plantio em junho de 1998.

2. Área 2: com $19.200 \mathrm{~m}^{2}$ e 3.276 mudas de E. urophylla $\times$ E. grandis, plantio em junho de 1998.

3. Área 3: com $12.300 \mathrm{~m}^{2}$ e 2.112 árvores de E. pilularis, plantio em junho de 1989.

4. Área 4: com $25.500 \mathrm{~m}^{2}$ e 4.233 mudas de E. urophylla, plantio em junho de 1999, na qual foi utilizado controle químico de cupins por imersão das mudas em deltametrina ( $350 \mathrm{ml}$ para $1.000 \mathrm{ml}$ água).

Todas as áreas apresentam relevo plano, vegetação anterior de campo sujo, preparo do solo com aração e gradagem, espaçamento no plantio de $3,0 \mathrm{~m} \times 2,0 \mathrm{~m}$ e, têm por objetivo, o melhoramento das espécies de eucalipto, através de testes de progênie. A vegetação adjacente das áreas de estudo é bastante variada (Figura 2). As áreas 1,2 e 3 localizam-se no talhão $7\left(241.600 \mathrm{~m}^{2}\right)$ e a 4 no talhão $12\left(93.000 \mathrm{~m}^{2}\right)$. 




Figura 1 - Áreas de estudo 1 e 2. 

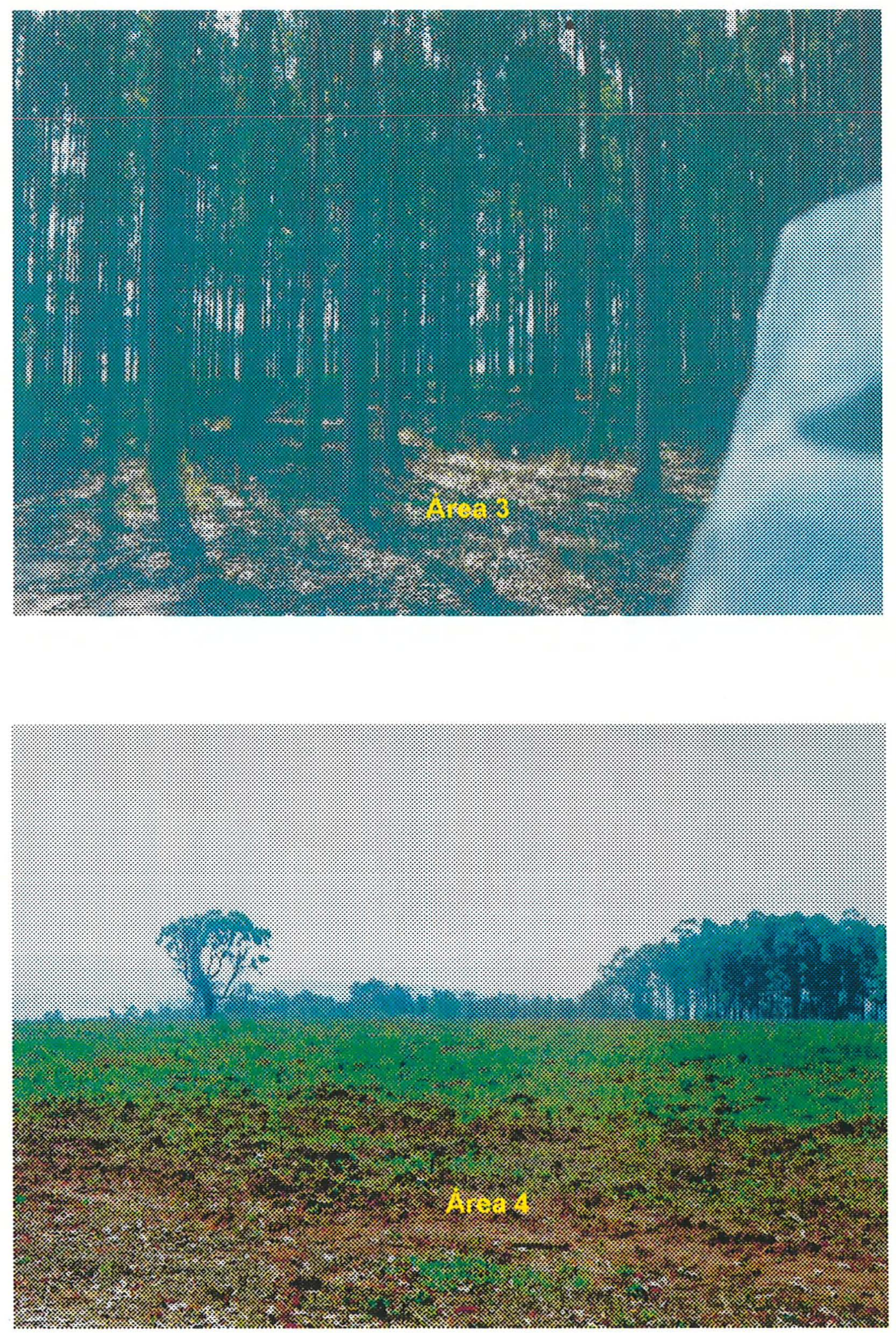

Figura 1 (continuação) - Áreas de estudo 3 e 4. 

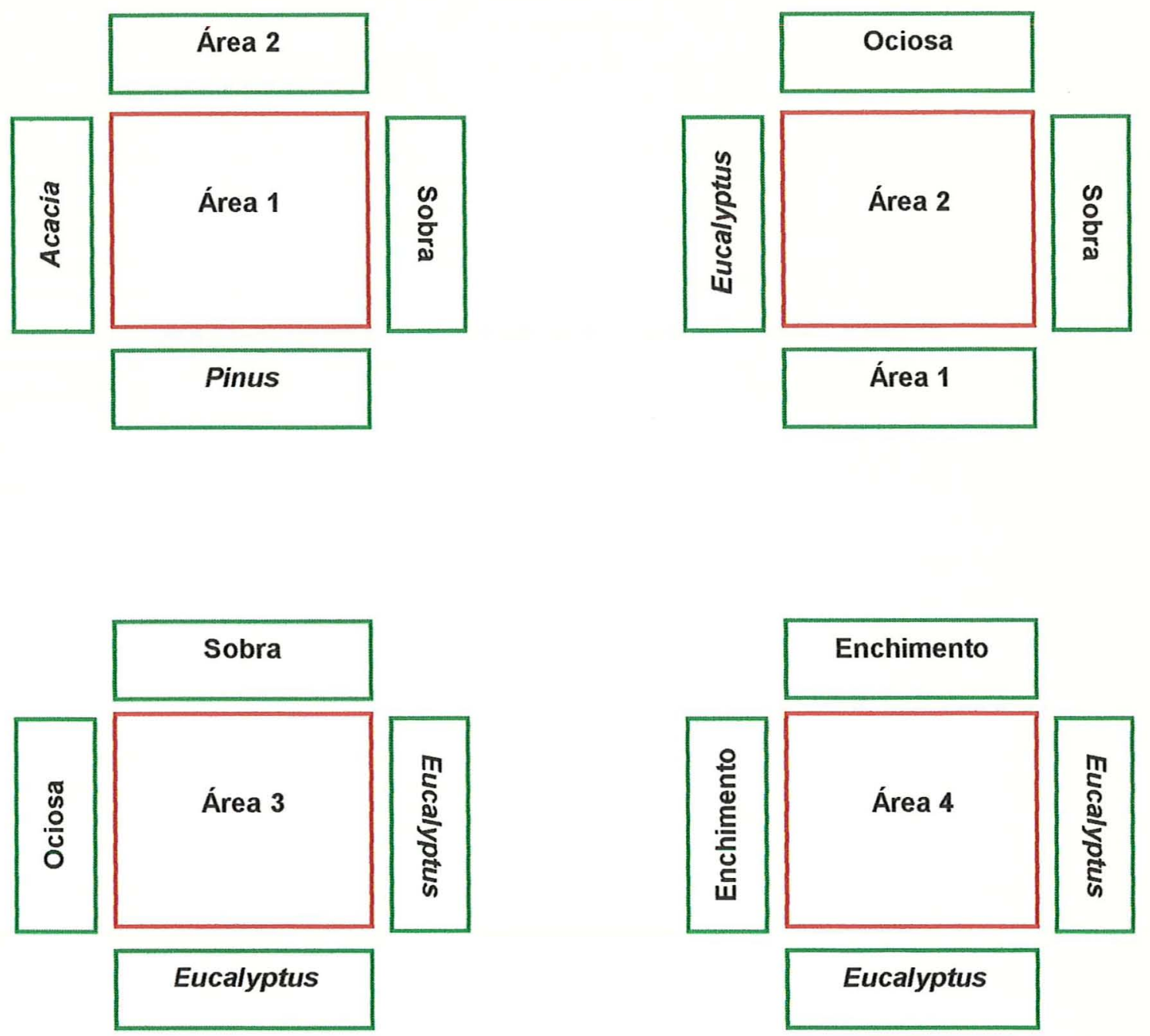

Figura 2 - Desenho esquemático da vegetação adjacente a cada área de estudo (não são consideradas as diferenças de tamanho e forma das áreas). Legenda:

- AcacialEucalyptus/Pinus: árvores com mais de cinco anos;

- sobra: local sem vegetação, a terra foi apenas preparada para o plantio de Eucalyptus;

- enchimento: mesma vegetação da área de estudo;

- ociosa: local com vegetação arbustiva nativa. 


\subsection{Levantamento das mudas atacadas por cupins}

Foi realizada contagem das mudas, que apresentavam caule e folhas ressecadas, facilmente arrancadas para a avaliação do sistema radicular, onde o ataque de cupins pode ser detectado. Não foram realizadas coletas de cupins durante este levantamento que, nas áreas 1 e 2, ocorreu em setembro de 1998 e, na 4, em agosto e setembro de 1999 (Quadro 1).

\subsection{Coleta de cupins com iscas Termitrap ${ }^{\circledR}$}

Foram utilizadas iscas do tipo Termitrap ${ }^{\circledR}$, de papelão corrugado, em forma de rolo, com $15 \mathrm{~cm}$ de altura e $8 \mathrm{~cm}$ de diâmetro, enterradas ao lado dos eucaliptos, em posição vertical, com a parte superior na mesma altura da superfície do solo (Figura 3 ).

A distribuição obedeceu a um padrão, com espaçamento de $10,0 \mathrm{~m} \times 9,0 \mathrm{~m}$ entre iscas (Figura 4), que permaneceram no campo por três semanas. Após este período, foram retiradas, puxando-se cuidadosamente a borda superior, que ficou exposta, evitando o manuseio da isca para não afugentar os cupins. A seguir, as iscas foram acondicionadas individualmente em sacos plásticos numerados, de acordo com - local de coleta, e transportadas para laboratório. No dia seguinte, as iscas foram abertas em bandeja branca e os cupins, quando presentes, contados. Uma parcela destes foi separada, para posterior identificação, em álcool $80 \%$. O número de iscas por área foi definido a partir do tamanho da mesma (Quadro 1). Nas áreas 1 e 2, as coletas ocorreram durante os meses de março, abril e maio de 1999 e, na 4, em agosto e setembro de 1999. 

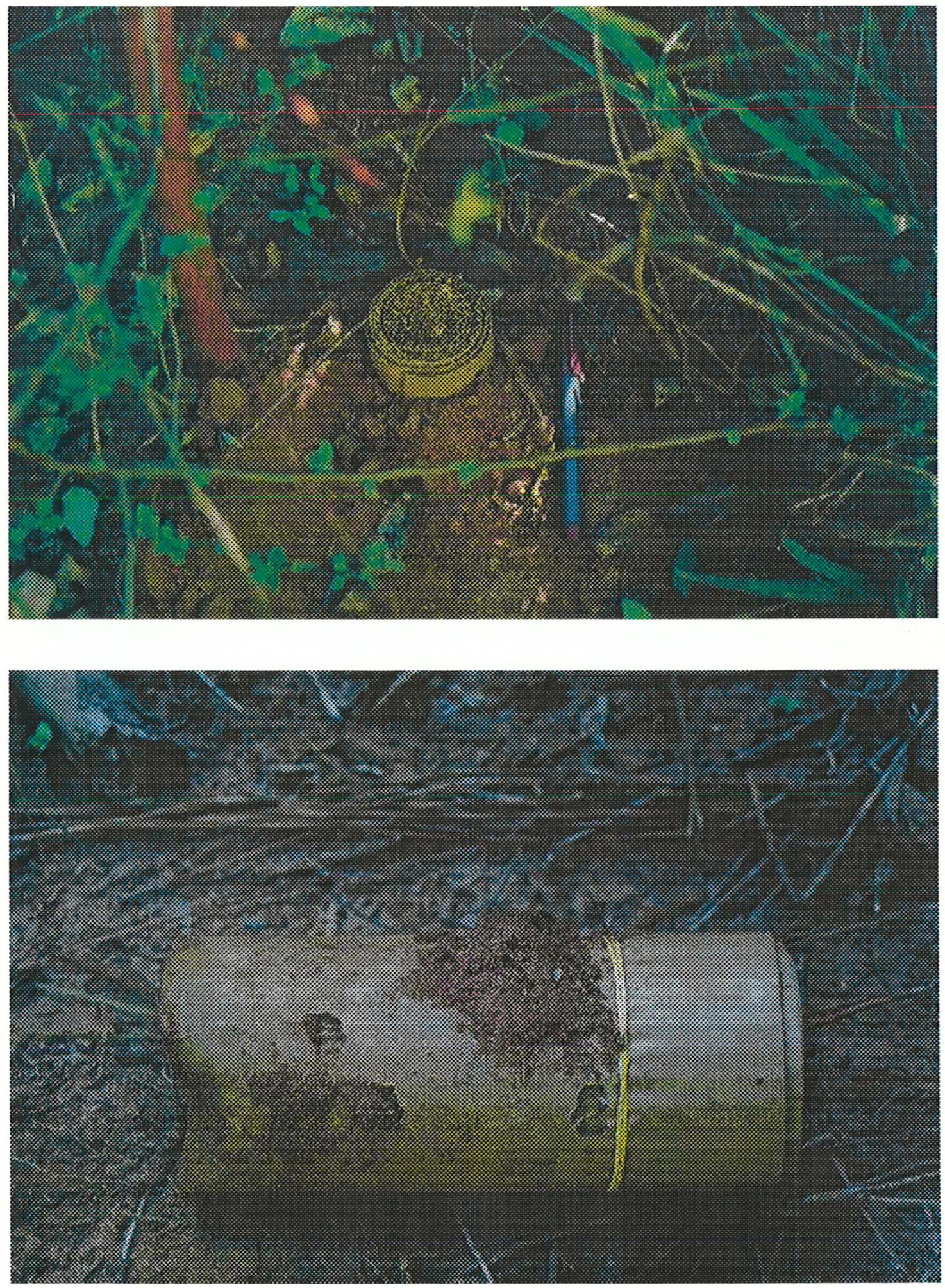

Figura 3 - Isca Termitrap ${ }^{\circledR}$ ao lado do eucalipto e após ser retirada do solo. 


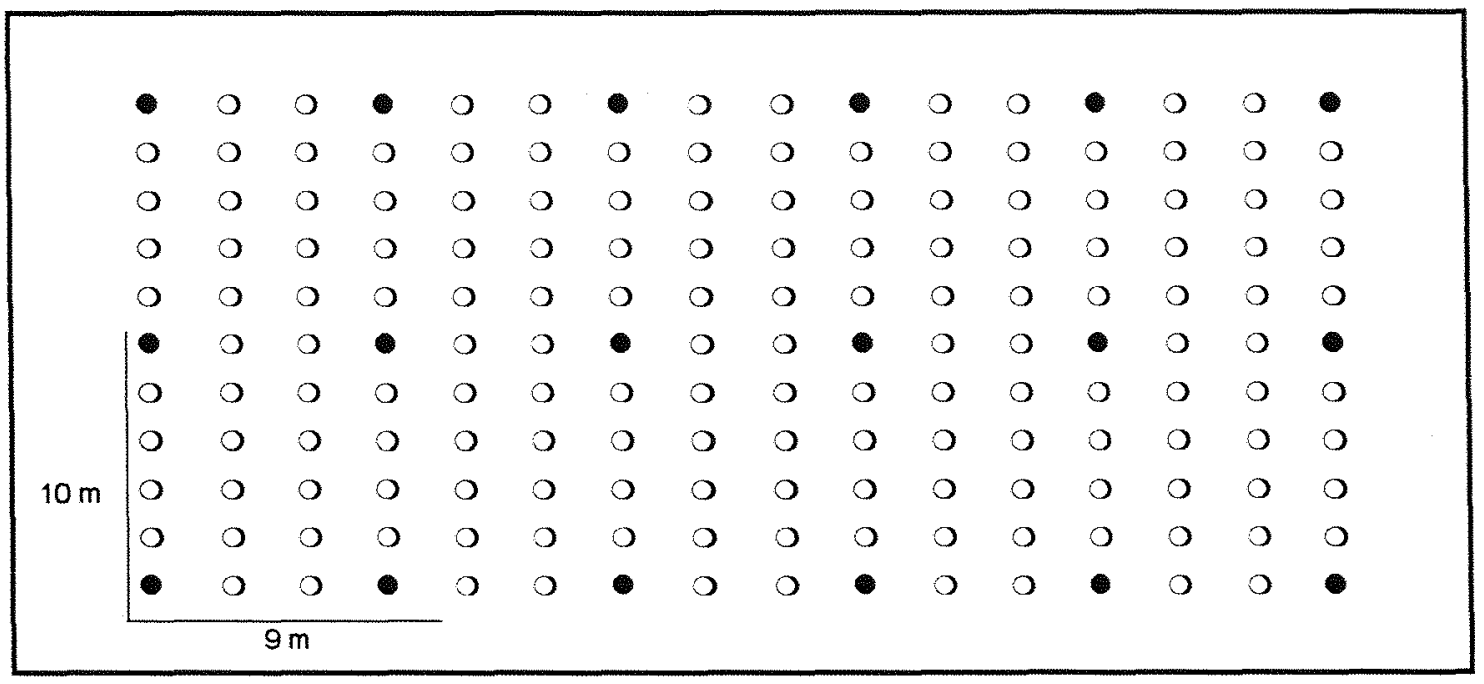

Figura 4 - Padrão de distribuição das iscas Termitrap ${ }^{\circledR}$ na parcela em campo:

o: árvores de eucalipto sem isca ao lado

- árvores de eucalipto com isca ao lado

\subsection{Coleta manual de cupins}

Durante os meses de janeiro e fevereiro de 1999, na Área 3, foram amostrados individuos dos ninhos de montículo e cupins presentes nas árvores (Figura 5). Para tanto, foi utilizada metodologia de transectos, avaliando uma fileira de árvores (de acordo com a linha de plantio), a cada intervalo de duas não avaliadas. O mesmo critério foi utilizado na escolha dos indivíduos de Eucalyptus, uma árvore amostrada para duas não amostradas. Assim, foram avaliadas 242 árvores das 2.112 presentes no plantio.

As árvores adultas tiveram a casca arrancada com auxilio de espátula e faca até a altura de aproximadamente $1 \mathrm{~m}$ e $50 \mathrm{~cm}$ a partir do solo. Foram coletados somente os cupins presentes sob ou sobre a casca das árvores desta região, não sendo amostrados indivíduos presentes no cerne, raizes ou dossel. Os cupins, quando encontrados, foram retirados com auxilio de pinça e pincel. As amostras foram transportadas para laboratório e acondicionadas em álcool $80 \%$. 
Para os cupins de montículo, foram considerados dois metros para as laterais (1,0 m para direita e $1,0 \mathrm{~m}$ para esquerda) da fileira de árvores escolhida e dois metros entre fileiras de árvores não amostradas (Figura 6).

Os ninhos foram abertos com picareta ou enxadão, e os cupins coletados no próprio local com 0 auxilio de pinça e pincel. As amostras foram transportadas para laboratório e acondicionadas em álcool $80 \%$.

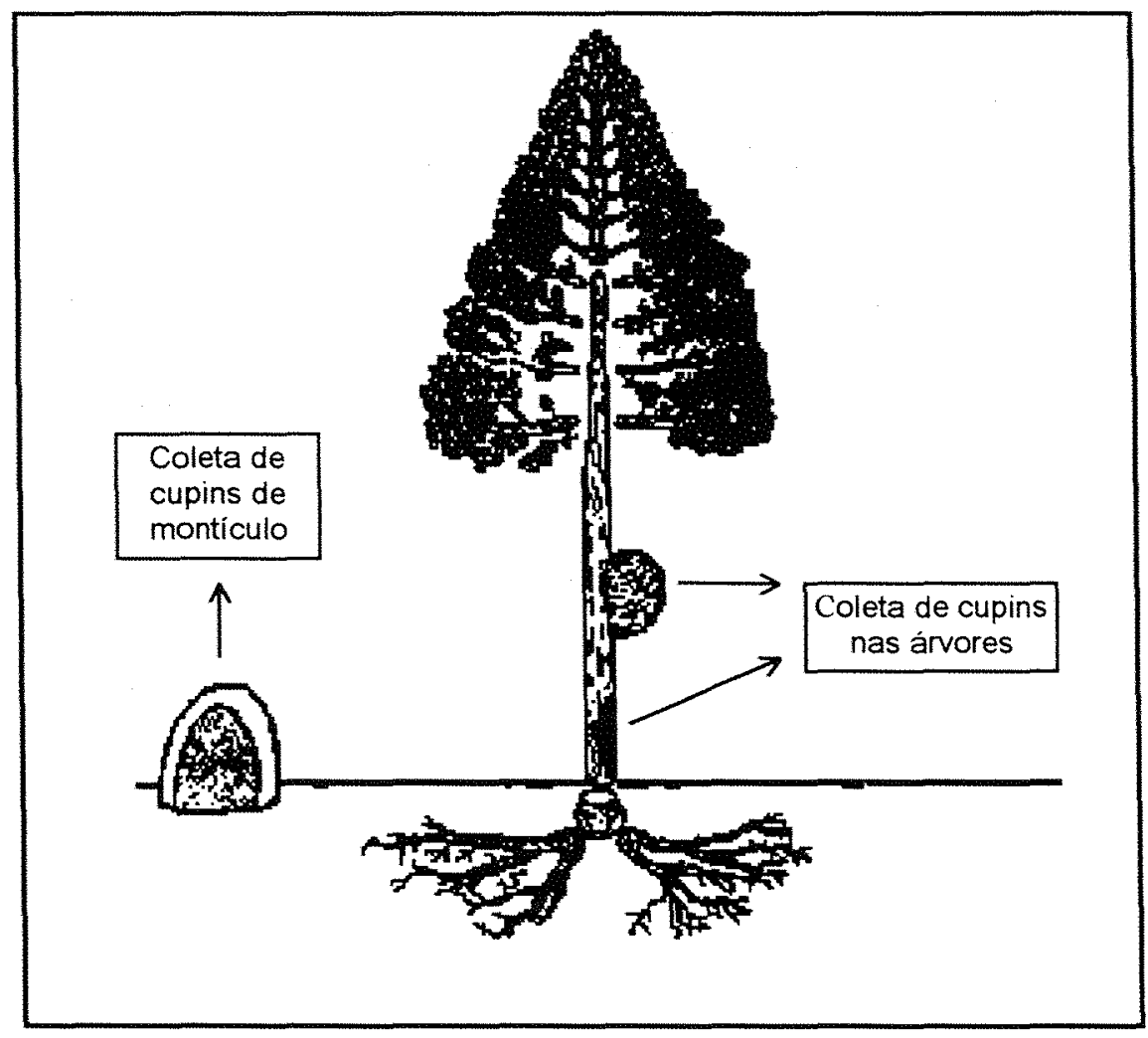

Figura 5 - Amostragem dos cupinzeiros de montículo e dos cupins presentes em Eucalyptus na Área 3 (modificado de BERTI FILHO, 1993). 


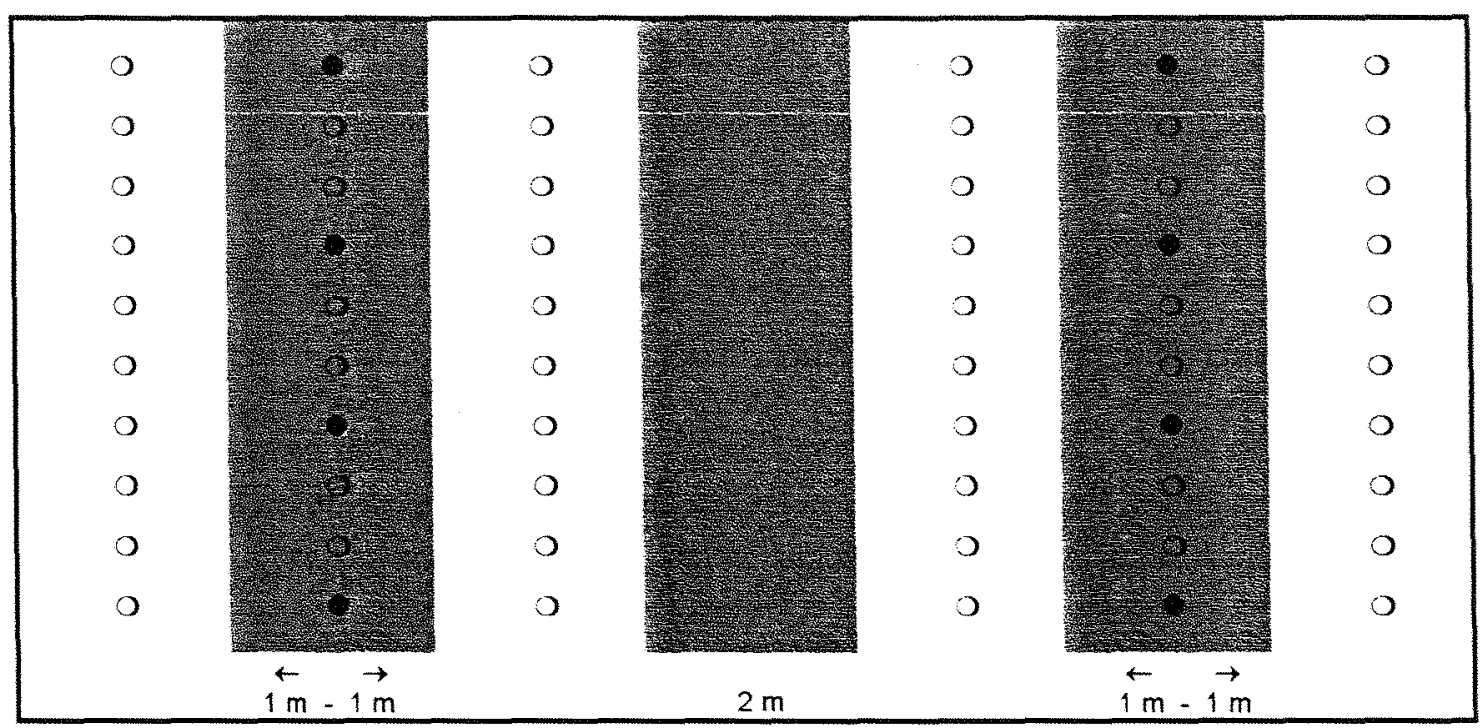

Figura 6 - Padrão de coleta de cupins nas árvores e em ninhos de montículo, considerando faixa de $2 \mathrm{~m}$ incluindo fileira amostrada e $2 \mathrm{~m}$ entre fileiras não amostradas:

O: árvores de Eucalyptus não avaliadas quanto a presença de cupins;

- árvores de Eucalyptus avaliadas quanto a presença de cupins;

- área de coleta dos cupins em ninhos de montículo.

Quadro 1 - Súmula da metodologia nas áreas de estudo.

\begin{tabular}{|l|c|c|c|c|}
\hline & AREA 1 & ÁREA 2 & AREA 3 & AREA 4 \\
\hline Espécie & Eucalyptus saligna & $\begin{array}{c}\text { E. urophylla } \\
\text { E. grandis }\end{array}$ & E. pilularis & E. urophylla \\
\hline Talhäo & 7 & 7 & 7 & 12 \\
\hline Data de plantio & junho de 1998 & junho de 1998 & junho de 1989 & junho de 1999 \\
\hline Espaçamento $(\mathrm{m})$ & $3,0 \times 2,0$ & $3,0 \times 2,0$ & $3,0 \times 2,0$ & $3,0 \times 2,0$ \\
\hline Metragem total $\left(\mathrm{m}^{2}\right)$ & 34.600 & 19.200 & 12.300 & 25.500 \\
\hline Total de mudas & 5.922 & 3.726 & - & 4.233 \\
\hline Total de árvores & - & - & 2.112 & - \\
\hline Mudas avaliadas & 5.922 & 3.276 & - & 4.233 \\
\hline Árvores avaliadas & - & - & 242 & - \\
\hline Total de iscas & 419 & 239 & 143 & 289 \\
\hline $\begin{array}{l}\text { Periodo de trabalho } \\
\text { na área }\end{array}$ & $\begin{array}{c}\text { setembro/1998 } \\
\text { março, abril e } \\
\text { maio/1999 }\end{array}$ & $\begin{array}{c}\text { setembro/1998 } \\
\text { março, abril e } \\
\text { maio/1999 }\end{array}$ & $\begin{array}{c}\text { janeiro, fevereiro e } \\
\text { junho/1999 }\end{array}$ & $\begin{array}{c}\text { agosto e } \\
\text { setembro/1999 }\end{array}$ \\
\hline
\end{tabular}




\subsection{Georeferenciamento das áreas de estudo}

Talhões e áreas de estudo foram georeferenciadas (latitude e longitude) em coordenadas UTM (Universal Transversa de Mercator) com tomada de quatro pontos limítrofes/áreas, utilizando-se o Global Position System (GPS), da marca Trimble, modelo Pathfinder Pro XRIXRS, com correção em tempo real (via satélite) que fornece precisão $<1,0 \mathrm{~m}$.

Em laboratório, através do Sistema de Informações Geográficas Spring 3.3 (1999), desenvolvido pelo Instituto Nacional de Pesquisas Espaciais (INPE) foram gerados mapas georeferenciados das áreas com grade irregular $3,0 \mathrm{~m} \times 2,0 \mathrm{~m}$, na escala 1:350. A grade forneceu o local de cada mudalárvore/isca nas áreas de estudo, já que o plantio destas obedece ao espaçamento $3,0 \mathrm{~m} \times 2,0 \mathrm{~m}$.

Os mapas das áreas com as grades foram plotados em tamanho $\mathrm{AO}$ e as mudas atacadas; as árvores contendo cupins; os ninhos de montículo e os locais das iscas foram marcados manualmente nas grades.

Para as iscas, foram atribuídas notas, de acordo com o número de cupins presentes (Quadro 2).

Quadro 2 - Notas das iscas de acordo com o número de cupins presentes.

\begin{tabular}{|c|c|c|}
\hline Nota & Número de cupins isca & Intervalo \\
\hline 0 & 0 & - \\
\hline 1 & 1 a 10 & 10 \\
\hline 2 & 11 a 20 & 10 \\
\hline 3 & 21 a 50 & 30 \\
\hline 4 & 51 a 100 & 50 \\
\hline 5 & 101 a 200 & 100 \\
\hline 6 & 201 a 300 & 100 \\
\hline 7 & 301 a 400 & 100 \\
\hline 8 & 401 a 500 & 100 \\
\hline 9 & 501 a 800 & 300 \\
\hline 10 & $>800$ & \\
\hline
\end{tabular}

Finalmente, estes dados foram digitalizados em mesa digitalizadora (Digigraf, tamanho $\mathrm{AO}$ ) e importados para o programa Spring 3.3, onde os novos mapas foram cruzados para fins comparativos. Como cada isca recebeu nota individual, de acordo com o número de cupins presentes, no momento da digitalização estas notas foram 
passadas para o programa, gerando mapas coloridos de acordo com as respectivas notas.

\subsection{Delineamento estatístico}

Devido ao fato de que na área 3 já existiam árvores e na área 4 houve controle químico durante o plantio das mudas, a comparação entre as quatro áreas tomou-se inviável. Por esse motivo, foram realizadas comparações apenas entre áreas 1 e 2 , e as áreas 3 e 4 serão apresentadas descritivamente.

Como não é possivel determinar a variação devida ao acaso, os efeitos que o fator áreas tem sobre as variáveis resposta estão confundidos com a variação ao acaso, tendo como conseqüência a impossibilidade de realizar a análise da variância e subseqüentes testes de comparações entre áreas.

As variáveis Ocorrência de Cupins nas Iscas, Mortalidade das Mudas e Freqüência de Cupins por Espécie, apesar de quantitativas, são de origem discreta, não paramétricas. Para este tipo de variável, a literatura estatística consultada (Burt, 1950; Andersen, 1991; Greenacre, 1993) sugere que os dados sejam tratados como dados categorizados, utilizando-se teste de independência. Assim, foram feitas tabelas de contingência para o cruzamento dessas variáveis com as áreas estudadas, e utilizada a estatistica $\chi^{2}$ (qui-quadrado) de Pearson para inferência sobre a independência ou não das variáveis cruzadas. As tabelas de contingência tomaram a seguinte forma:

\begin{tabular}{|c|c|c|c|c|c|}
\hline \multirow{2}{*}{$\begin{array}{l}\text { VARIÁVEL } \\
X_{i}\end{array}$} & \multicolumn{4}{|c|}{ VARIÁVEL $Z_{j}$} & \multirow{2}{*}{$\begin{array}{l}\text { TOTAL } \\
\text { DEX }\end{array}$} \\
\hline & $z_{1}$ & $z_{2}$ & $\ldots$ & $\mathrm{z}$ & \\
\hline$x_{1}$ & $y_{11}$ & $y_{12}$ & . & $y_{1 \mathrm{~J}}$ & $y_{1 .}$ \\
\hline$x_{2}$ & $y_{21}$ & $y_{22}$ & $\cdots$ & $y_{2 J}$ & $y_{2}$ \\
\hline$\ldots$ & $\ldots$ & $\ldots$ & $\ldots$ & $\ldots$ & $\ldots$ \\
\hline$x_{1}$ & $y_{11}$ & $y_{12}$ & $\cdots$ & $y_{1 J}$ & $y_{1 .}$ \\
\hline TOTAL DE Z & $y_{01}$ & $y .2$ & $\ldots$ & y.J & $n$ \\
\hline
\end{tabular}

onde:

- $\quad y_{i j}=$ freqüência observada de ocorrência do i-ésimo nivel da variável $X$ com o jésimo nível da variável $Z$ (ex.: Ocorrência de Cupins em Área com E. saligna);

- $\quad-y_{i \bullet}=$ total de ocorrência do i-ésimo nivel de $X$ (ex.: Ocorrência ou não de Cupins), ou marginal de $X$; 
- $-y_{\bullet j}=$ total de ocorrência do j-ésimo nível de $Z$ (ex.: Área com E. saligna), ou marginal de $Z$;

- $\quad-n=$ total de observações da amostra (Iscas).

A estatística $\chi^{2}$ é obtida da seguinte maneira:

$$
\chi_{o b s}^{2}=\sum_{i j} \frac{\left(y_{i j}-e_{i j}\right)^{2}}{e_{i j}}
$$

onde $e_{i j}=$ freqüência esperada de ocorrências do cruzamento da variável $X$ (ex.: área com E. saligna) com a variável $Z$ (ex.: ocorrência ou não de cupins), na amostra, se as variáveis cruzadas forem independentes. Essa estatística tem distribuição de $\chi^{2}$ com $(I-1)(J-1)$ graus de liberdade $(I=$ número de niveis da variável $X$ e $J=$ número de níveis da variável $Z$ ), ou seja, o valor de $\chi^{2}$ observado será comparado com um valor tabelado a um nível $\alpha$ de erro e os graus de liberdade associados às duas categorizações. Assim, se $\chi_{\mathrm{obs}}^{2}>\chi_{\mathrm{tab}\left(5^{\circ}\right)}^{2}(\alpha \leq 0,05)$, rejeita-se a hipótese de independência (ou de relação) entre as variáveis a um nivel de $5 \%$. Se $\chi_{\mathrm{obs}}^{2}>\chi_{\mathrm{tab}(1 \%)}^{2}$ $(\alpha \leq 0,01)$, rejeita-se a hipótese de independência entre as variáveis a um nível de $1 \%$.

Considerando-se como nível mínimo de significância (máximo de erro) de $5 \%$, se $\chi_{\text {obs }}^{2}<\chi_{\operatorname{tab}\left(5^{\circ}\right)}^{2}(\alpha>0,05)$ não se rejeita a hipótese de independência entre as variáveis, ou seja, por exemplo, a ocorrência de cupins não depende das áreas de Eucalyptus.

Sob a hipótese de independência entre as variáveis cruzadas, a freqüência esperada é obtida da seguinte forma:

$$
e_{i j}=\text { produto das marginais }
$$

$n$

ou seja, para se calcular, por exemplo, a freqüência esperada de ocorrência de cupins na área com E. saligna,

$$
e_{i j}=\frac{\text { total de iscas na área com } E \text {. saligna } x \text { total de ocorrência de cupins }}{\text { total de iscas }}
$$




\section{RESULTADOS E DISCUSSÃO}

\section{1 Área 1}

$\mathrm{Na}$ área 1, do total de 5.922 mudas avaliadas, 656 foram atacadas por cupins, com destruição do sistema radicular e morte da planta, o que representa perda de $11,08 \%$ do plantio.

Ao término de três semanas, das 419 iscas instaladas, 4,29\% apresentaram cupins (Tabela 1), tendo sido encontrada uma espécie do gênero Embiratermes em três amostras; uma espécie do gênero Cornitermes em sete amostras e a espécie Heterotermes tenuis em oito amostras.

Tabela 1. Cupins coletados em isca Termitrap ${ }^{\circledR}$ na área 1.

\begin{tabular}{|c|c|c|c|c|}
\hline Identificação & $\begin{array}{c}\mathrm{N}^{\circ} \mathrm{da} \\
\text { Amostra }\end{array}$ & $\begin{array}{c}\mathrm{N}^{0} \text { de } \\
\text { Individuos }\end{array}$ & Operários & Soldados \\
\hline \multicolumn{5}{|l|}{ Termitidae } \\
\hline \multicolumn{5}{|l|}{ Nasutitermitinae } \\
\hline Embiratermes sp. & 40 & 1 & $x$ & \\
\hline Embiratermes sp. & 50 & 9 & $x$ & \\
\hline Embiratermes sp. & 58 & 9 & $x$ & \\
\hline Cornitermes sp. & 41 & 36 & $x$ & \\
\hline Cornitermes sp. & 43 & 13 & $x$ & \\
\hline Comitermes sp. & 44 & 15 & $x$ & \\
\hline Cornitermes sp. & 45 & 37 & $x$ & \\
\hline Comitermes sp. & 47 & 68 & $x$ & \\
\hline Comitermes sp. & 57 & 1 & $x$ & \\
\hline Comitermes sp. & 59 & 6 & $x$ & \\
\hline \multirow{2}{*}{\multicolumn{5}{|c|}{$\begin{array}{l}\text { Rhinotermitidae } \\
\text { Heterotermitinae }\end{array}$}} \\
\hline & & & & \\
\hline Heterotermes tenuis & 42 & $>1000$ & $x$ & $x$ \\
\hline H. tenuis & 48 & 55 & $x$ & $x$ \\
\hline H. tenuis & 51 & $>1000$ & $x$ & $x$ \\
\hline H. tenuis & 52 & $>1000$ & $x$ & $x$ \\
\hline H. tenuis & 53 & $>1000$ & $x$ & $x$ \\
\hline$H$. tenuis & 54 & $>1000$ & $x$ & $x$ \\
\hline H. tenuis & 55 & $500-800$ & $x$ & $x$ \\
\hline H. tenuis & $\infty$ & $500-800$ & $x$ & $x$ \\
\hline TOTAL DE AMOSTRAS & 18 & & & \\
\hline
\end{tabular}




\section{2 Área 2}

Na área 2, do total de 3.276 mudas avaliadas, 300 foram atacadas por cupins, com destruição do sistema radicular e morte da planta, representando perda de $9,15 \%$ do plantio.

Das 239 iscas instaladas, 2,09\% apresentaram cupins ao término de três semanas (Tabela 2), tendo sido encontrados indivíduos da subfamília Apicotermitinae em duas amostras; a espécie Cornitermes cumulans em uma amostra e Heterotermes tenuis em duas amostras.

Tabela 2. Cupins coletados em isca Termitrap ${ }^{\oplus}$ na área 2.

\begin{tabular}{|c|c|c|c|c|}
\hline Identificação & $\begin{array}{c}N^{\circ} \text { da } \\
\text { Amostra }\end{array}$ & $\begin{array}{c}N^{\circ} \text { de } \\
\text { Individuos }\end{array}$ & Operários & Soldados \\
\hline \multicolumn{5}{|l|}{ Termitidae } \\
\hline Apicotermitinae & 56 & 16 & $x$ & \\
\hline Apicotermitinae & 64 & 25 & $x$ & \\
\hline \multicolumn{5}{|l|}{ Nasutitermitinae } \\
\hline Comitemes cumulans & 46 & 52 & $x$ & $\mathrm{x}$ \\
\hline \multicolumn{5}{|l|}{$\begin{array}{l}\text { Rhinotermitidae } \\
\text { Hetermermitinat }\end{array}$} \\
\hline Heterotermes tenuis & 49 & 233 & $x$ & $x$ \\
\hline H. tenuis & 62 & $>1000$ & $x$ & $x$ \\
\hline TOTAL DE AMOSTRAS & 5 & & & \\
\hline
\end{tabular}

\section{3 Área 3}

$\mathrm{Na}$ área 3 , foram amostrados cupins presentes sob ou sobre a casca das árvores e cupins de montículo. Das 239 árvores avaliadas, $4,18 \%$ apresentaram cupins sob a casca, tendo sido encontrada uma espécie do gênero Comitermes em uma árvore e a espécie Heterotermes tenuis em nove árvores.

Para os cupins de montículo, foram encontrados dois ninhos de C. bequaerti, 25 de C. cumulans e dois de Diversitermes diversimilis. Não foram encontrados cupins com ninhos arbóreos nesta área (Tabela 3). 
Tabela 3. Coleta manual de cupins da área 3.

\begin{tabular}{|c|c|c|c|c|c|}
\hline Identificação & $\begin{array}{c}N^{\circ} \text { da } \\
\text { Amostra }\end{array}$ & Montículo & Arvore & Operários & Soldados \\
\hline \multicolumn{6}{|l|}{ Termitidae } \\
\hline \multicolumn{6}{|l|}{ Nasutitermitinae } \\
\hline Comitermes sp. & 13 & & $x$ & $x$ & $x$ \\
\hline C. bequaerti & 1 & $x$ & & $x$ & $x$ \\
\hline C. bequaerti & 7 & $x$ & & $x$ & $\mathrm{x}$ \\
\hline c. cumulans & 2 & $x$ & & $x$ & $x$ \\
\hline C. cumulans & 3 & $x$ & & $\mathrm{x}$ & $x$ \\
\hline C. cumulans & 4 & $x$ & & $x$ & $x$ \\
\hline C. cumulans & 5 & $x$ & & $x$ & $x$ \\
\hline C. cumulans & 6 & $x$ & & $x$ & $x$ \\
\hline C. cumulans & 8 & $x$ & & $x$ & $x$ \\
\hline C. cumulans & 9 & $x$ & & $x$ & $x$ \\
\hline c. cumulans & 10 & $x$ & & $x$ & $x$ \\
\hline C. cumulans & 11 & $x$ & & $x$ & $x$ \\
\hline C. cumulans & 14 & $x$ & & $x$ & $x$ \\
\hline C. cumulans & 15 & $x$ & & $x$ & $x$ \\
\hline C. cumulans & 17 & $x$ & & $\mathrm{x}$ & $x$ \\
\hline C. cumulans & 18 & $x$ & & $x$ & $x$ \\
\hline C. cumulans & 21 & $x$ & & $x$ & $x$ \\
\hline C. cumulans & 27 & $x$ & & $x$ & $x$ \\
\hline C. cumulans & 28 & $x$ & & $x$ & $x$ \\
\hline C. cumulans & 29 & $x$ & & $x$ & $x$ \\
\hline C. cumulans & 30 & $x$ & & $x$ & $x$ \\
\hline C. cumulans & 33 & $x$ & & $x$ & $x$ \\
\hline C. cumulans & 34 & $x$ & & $x$ & $x$ \\
\hline C. cumulans & 35 & $x$ & & $x$ & $x$ \\
\hline C. cumulans & 36 & $x$ & & $x$ & $x$ \\
\hline C. cumulans & 37 & $x$ & & $x$ & $x$ \\
\hline C. cumulans & 38 & $x$ & & $x$ & $x$ \\
\hline C. cumulans & 39 & $x$ & & $x$ & $x$ \\
\hline Diversitermes diversimiles & 16 & $\mathbf{x}$ & & $x$ & $\mathbf{x}$ \\
\hline D. diversimiles & 25 & $x$ & & $x$ & $x$ \\
\hline \multicolumn{6}{|l|}{ Rhinotermitidae } \\
\hline \multicolumn{6}{|l|}{ Heterotermitinae } \\
\hline Heterotermes tenuis & 12 & & $x$ & $x$ & $x$ \\
\hline H. tenuis & 19 & & $x$ & $x$ & $x$ \\
\hline H. tenuis & 20 & & $x$ & $x$ & $x$ \\
\hline H. tenuis & 22 & & $x$ & $x$ & $x$ \\
\hline H. tenuis & 23 & & $x$ & $x$ & $x$ \\
\hline H. tenuis & 24 & & $x$ & $x$ & $x$ \\
\hline H. tenuis & 26 & & $x$ & $x$ & $x$ \\
\hline H. tenuis & 31 & & $x$ & $x$ & $x$ \\
\hline H. tenuis & 32 & & $x$ & $x$ & $x$ \\
\hline TOTAL DE AMOSTRAS & 39 & & & & \\
\hline
\end{tabular}

Ao término de três semanas, das 143 iscas instaladas, 9,97\% apresentaram cupins (Tabela 4), tendo sido encontrada uma espécie do gênero Araujotermes em cinco amostras; a espécie Diversitermes diversimiles em quatro amostras e Heterotermes tenuis em cinco amostras. 
Tabela 4. Cupins coletados em isca Termitrap ${ }^{\circledR}$ na área 3.

\begin{tabular}{|c|c|c|c|c|}
\hline Identificaçāo & $\begin{array}{c}N^{\circ} \text { da } \\
\text { Amostra }\end{array}$ & $\begin{array}{l}\mathrm{N}^{\circ} \text { de } \\
\text { Individuos }\end{array}$ & Operários & Soldados \\
\hline \multicolumn{5}{|l|}{ Termitidae } \\
\hline \multicolumn{5}{|l|}{ Nasutitermitinae } \\
\hline Araujotermes sp. & 67 & 10 & $x$ & $x$ \\
\hline Araujotermes sp. & 71 & 40 & $x$ & $x$ \\
\hline Araujotermes sp. & 72 & $>1000$ & $x$ & $x$ \\
\hline Araujotermes sp. & 73 & $>1000$ & $x$ & $x$ \\
\hline Araujotermes sp. & 75 & 50 & $x$ & $x$ \\
\hline Diversitermes diversimiles & 6 & 112 & $x$ & $x$ \\
\hline D. diversimiles & 66 & $>1000$ & $x$ & $x$ \\
\hline D. diversimiles & $\infty$ & $>1000$ & $x$ & $x$ \\
\hline D. diversimiles & 74 & $>1000$ & $x$ & $x$ \\
\hline \multicolumn{5}{|l|}{$\begin{array}{l}\text { Rhinotermitidae } \\
\text { Heterotermitinae }\end{array}$} \\
\hline Heterotermes tenuis & $\mathfrak{3}$ & $>1000$ & $x$ & $x$ \\
\hline$H$. tenuis & 64 & $>1000$ & $x$ & $x$ \\
\hline H. tenuis & 68 & $>1000$ & $x$ & $x$ \\
\hline H. tenuis & 70 & $>1000$ & $x$ & $x$ \\
\hline H. tenuis & 76 & $>1000$ & $x$ & $x$ \\
\hline TOTAL DE AMOSTRAS & 14 & & & \\
\hline
\end{tabular}

\section{4 Área 4}

Das 4.233 mudas avaliadas na área 4, nenhuma apresentou evidências do ataque por cupins.

Ao término de três semanas, das 289 iscas instaladas na área 4, 3,11\% apresentaram cupins (Tabela 5), tendo sido encontrada uma espécie do gênero Cornitermes em uma amostra; a espécie C. cumulans em seis amostras e Heterotermes tenuis em duas amostras.

Tabela 5. Cupins coletados em isca Termitrap ${ }^{\circledR}$ na área 4.

\begin{tabular}{|c|c|c|c|c|}
\hline Identificação & $\begin{array}{c}\mathrm{N}^{\circ} \mathrm{da} \\
\text { Amostra }\end{array}$ & $\begin{array}{c}\mathrm{N}^{\circ} \text { de } \\
\text { Individuos }\end{array}$ & Operários & Soldados \\
\hline \multicolumn{5}{|l|}{$\begin{array}{l}\text { Termitidae } \\
\text { Nasutitermitinae }\end{array}$} \\
\hline & $\begin{array}{l}80 \\
70\end{array}$ & $>1000$ & $x$ & \\
\hline $\begin{array}{l}\text { C. cumulans } \\
\text { C. cumulans }\end{array}$ & $\begin{array}{l}79 \\
81\end{array}$ & $\begin{array}{c}50 \\
>1000\end{array}$ & $x$ & $x$ \\
\hline $\begin{array}{l}\text { C. cumulans } \\
\text { C. cumulans }\end{array}$ & $\begin{array}{l}81 \\
82\end{array}$ & $\begin{array}{c}>1000 \\
12\end{array}$ & $x$ & $x$ \\
\hline C. cumulans & 83 & $\begin{array}{l}12 \\
91\end{array}$ & $\begin{array}{l}x \\
x\end{array}$ & $\begin{array}{l}x \\
x\end{array}$ \\
\hline C. cumulans & 84 & 63 & $x$ & $x$ \\
\hline C. cumulans & 85 & 125 & $x$ & $x$ \\
\hline \multicolumn{5}{|l|}{$\begin{array}{l}\text { Rhinotermitidae } \\
\text { Heterotermitinae }\end{array}$} \\
\hline Heterotermes tenuis & 77 & $>1000$ & $x$ & $x$ \\
\hline H. tenuis & 78 & $>1000$ & $x$ & $x$ \\
\hline TOTAL DE AMOSTRAS & 9 & & & \\
\hline
\end{tabular}


Quando são consideradas coletas por áreas, a área 3 destaca-se com o maior número de espécies. Nas coletas com iscas, todas as áreas apresentaram um total de três espécies amostradas, contra cinco na coleta manual (Tabela 6).

O total de iscas colocadas nas quatro áreas de estudo foi de 1.090, destas, $4,22 \%$ apresentaram cupins. A área $1 \mathrm{com} 4,29 \%$, a área $2 \mathrm{com} 2,09 \%$, a área $3 \mathrm{com}$ $9,79 \%$ e a área 4 com $3,11 \%$ (Tabela 7 ).

Tabela 6. Cupins coletados nas quatro áreas de estudo.

\begin{tabular}{|c|c|c|c|c|c|}
\hline \multirow[t]{2}{*}{ Identificação } & \multirow{2}{*}{$\begin{array}{c}\text { AREA 1 } \\
\text { Iscas }\end{array}$} & \multirow{2}{*}{$\begin{array}{c}\text { AREA 2 } \\
\text { Iscas }\end{array}$} & \multicolumn{2}{|c|}{ AREA 3} & \multirow{2}{*}{$\frac{\text { AREA 4 }}{\text { Iscas }}$} \\
\hline & & & Iscas & $\begin{array}{l}\text { Coleta } \\
\text { manual }\end{array}$ & \\
\hline \multicolumn{6}{|l|}{ Termitidae } \\
\hline Apicotermitinae & & $x$ & & & \\
\hline \multicolumn{6}{|l|}{ Nasutitermitinae } \\
\hline Araujotermes sp. & & & $x$ & & \\
\hline Comitermes sp. & $x$ & & & $x$ & $x$ \\
\hline C. bequaerti & & & & $x$ & \\
\hline C. cumulans & & $x$ & & $x$ & $x$ \\
\hline Embiratermes sp. & $x$ & & & & \\
\hline Diversitermes diversimiles & & & $x$ & $x$ & \\
\hline \multicolumn{6}{|l|}{ Rhinotermitidae } \\
\hline Heterotermitinae & & & & & \\
\hline Heterotermes tenuis & $x$ & $\mathbf{x}$ & $\mathrm{x}$ & $x$ & $\mathbf{x}$ \\
\hline TOTAL DE ESPECIES & 3 & 3 & 3 & 5 & 3 \\
\hline
\end{tabular}

Tabela 7. Freqüências, absolutas e relativas, por fileira, de iscas colocadas e de iscas atacadas por cupins nas quatro áreas de estudo.

\begin{tabular}{|c|c|c|c|c|c|c|c|c|c|c|c|c|}
\hline \multirow[b]{3}{*}{ Fileira } & \multicolumn{3}{|c|}{$\begin{array}{l}\text { AREA 1 } \\
\text { E. saligna } \\
\text { Iscas }\end{array}$} & \multicolumn{3}{|c|}{$\begin{array}{c}\text { AREA } 2 \\
\begin{array}{c}\text { E. urophylla } \times \text { E. grandis } \\
\text { Iscas }\end{array}\end{array}$} & \multicolumn{3}{|c|}{$\begin{array}{l}\text { AREA } 3 \\
\begin{array}{l}\text { E. pilulares } \\
\text { Iscas }\end{array}\end{array}$} & \multicolumn{3}{|c|}{$\begin{array}{l}\text { AREA 4 } \\
\begin{array}{l}\text { E. urophylla } \\
\text { Iscas }\end{array}\end{array}$} \\
\hline & \multirow{2}{*}{$\frac{\mathrm{Col}}{\mathrm{N}}$} & \multicolumn{2}{|c|}{ Atacadas } & \multirow{2}{*}{$\frac{\mathrm{Col}}{\mathrm{N}}$} & \multicolumn{2}{|c|}{ Atacadas } & \multirow{2}{*}{$\frac{\mathrm{Col}}{\mathrm{N}}$} & \multicolumn{2}{|c|}{ Atacadas } & \multirow{2}{*}{$\frac{\mathrm{Col}}{\mathrm{N}}$} & \multicolumn{2}{|c|}{ Atacadas } \\
\hline & & $N$ & $\%$ & & $\mathrm{~N}$ & $\%$ & & $N$ & $\%$ & & $\mathrm{~N}$ & $\%$ \\
\hline 01 & 24 & 1 & 4,16 & 13 & 0 & - & 13 & 2 & 15,38 & 17 & 0 & - \\
\hline 04 & 24 & 5 & 20,00 & 13 & 1 & 7,69 & 13 & 1 & 7,69 & 17 & 1 & 5,88 \\
\hline 07 & 24 & 2 & 8,33 & 13 & 1 & 7,69 & 13 & 1 & 7,69 & 17 & 0 & - \\
\hline 10 & 24 & 2 & 8,33 & 13 & 0 & - & 13 & 1 & 7,69 & 17 & 1 & 5,88 \\
\hline 13 & 19 & 0 & - & 11 & 0 & - & 13 & 2 & 15,38 & 17 & 0 & $=$ \\
\hline 16 & 19 & 1 & 4,16 & 11 & 0 & - & 13 & 0 & - & 17 & 0 & - \\
\hline 19 & 19 & 1 & 4,16 & 11 & 0 & - & 13 & 1 & 7,69 & 17 & 0 & - \\
\hline 22 & 19 & 0 & - & 11 & 0 & - & 13 & 2 & 15,38 & 17 & 0 & - \\
\hline 25 & 19 & 0 & - & 11 & 0 & - & 13 & 1 & 7,69 & 17 & 1 & 5,88 \\
\hline 28 & 19 & 0 & - & 11 & 0 & - & 13 & 1 & 7,69 & 17 & 1 & 5,88 \\
\hline 31 & 19 & 2 & 8,33 & 11 & 0 & - & 13 & 2 & 15,38 & 17 & 0 & - \\
\hline 34 & 19 & 1 & 4,16 & 11 & 1 & 9,09 & - & - & - & 17 & 0 & - \\
\hline 37 & 19 & 2 & 8,33 & 11 & 0 & - & - & - & - & 17 & 0 & - \\
\hline 40 & 19 & 1 & 4,16 & 11 & 0 & - & - & - & - & 17 & 0 & - \\
\hline 43 & 19 & 0 & - & 11 & 0 & - & - & - & - & 17 & 1 & 5,88 \\
\hline 46 & 19 & 0 & - & 11 & 2 & 18,18 & - & - & - & 17 & 1 & 5,88 \\
\hline 49 & 19 & 0 & - & 11 & 0 & - & - & - & - & 17 & 3 & 17,64 \\
\hline 52 & 19 & 0 & - & 11 & 0 & - & - & - & - & - & - & - \\
\hline 55 & 19 & 0 & - & 11 & 0 & - & - & - & - & - & - & - \\
\hline 58 & 19 & 0 & - & 11 & 0 & - & - & - & - & - & - & - \\
\hline 61 & 19 & 0 & - & 11 & 0 & - & - & - & $=$ & $=$ & - & - \\
\hline TOTAL & 419 & 18 & 4,29 & 239 & 5 & 2,09 & 143 & 14 & 9,79 & 289 & 9 & 3,11 \\
\hline
\end{tabular}




\subsection{Georeferenciamento das áreas de estudo}

Os talhões e as quatro áreas de estudo foram georeferenciadas, fornecendo figura de posicionamento das mesmas entre si e no respectivo talhão (Figura 7).

Para as áreas 1 e 2 foram geradas figuras de distribuição das mudas mortas por ataque de cupins no plantio (Figura 8 e 10) e figuras localizando as iscas com cupins, coloridas de acordo com a nota atribuída a cada isca, referente ao número de cupins presentes (Figura 9 e 11).

$\mathrm{Na}$ área 3 foi gerada figura com ninhos de montículo encontrados e com as árvores que apresentavam cupins sob a casca (Figura 12). A seguir, também foi criada figura localizando as iscas atacadas por cupins, coloridas de acordo com a nota atribuída a cada isca, referente ao número de cupins presentes (Figura 13).

Já a área 4 , onde não foram constatadas mudas mortas devido a ação de cupins, possui somente figura localizando as iscas atacadas, coloridas de acordo com a sua respectiva nota (Figura 14). 


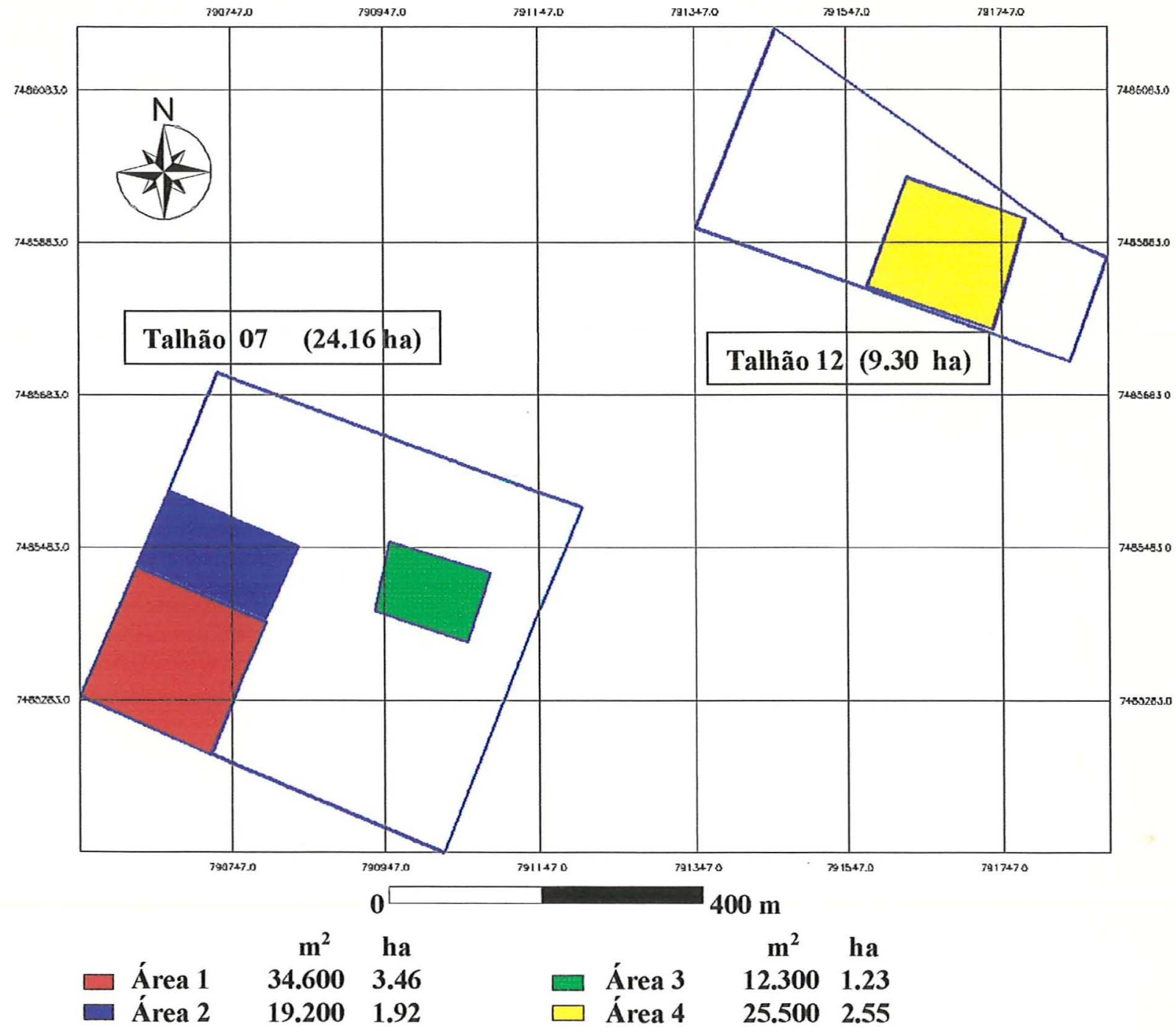

Figura 7 - Posicionamento das áreas nos respectivos talhões. 


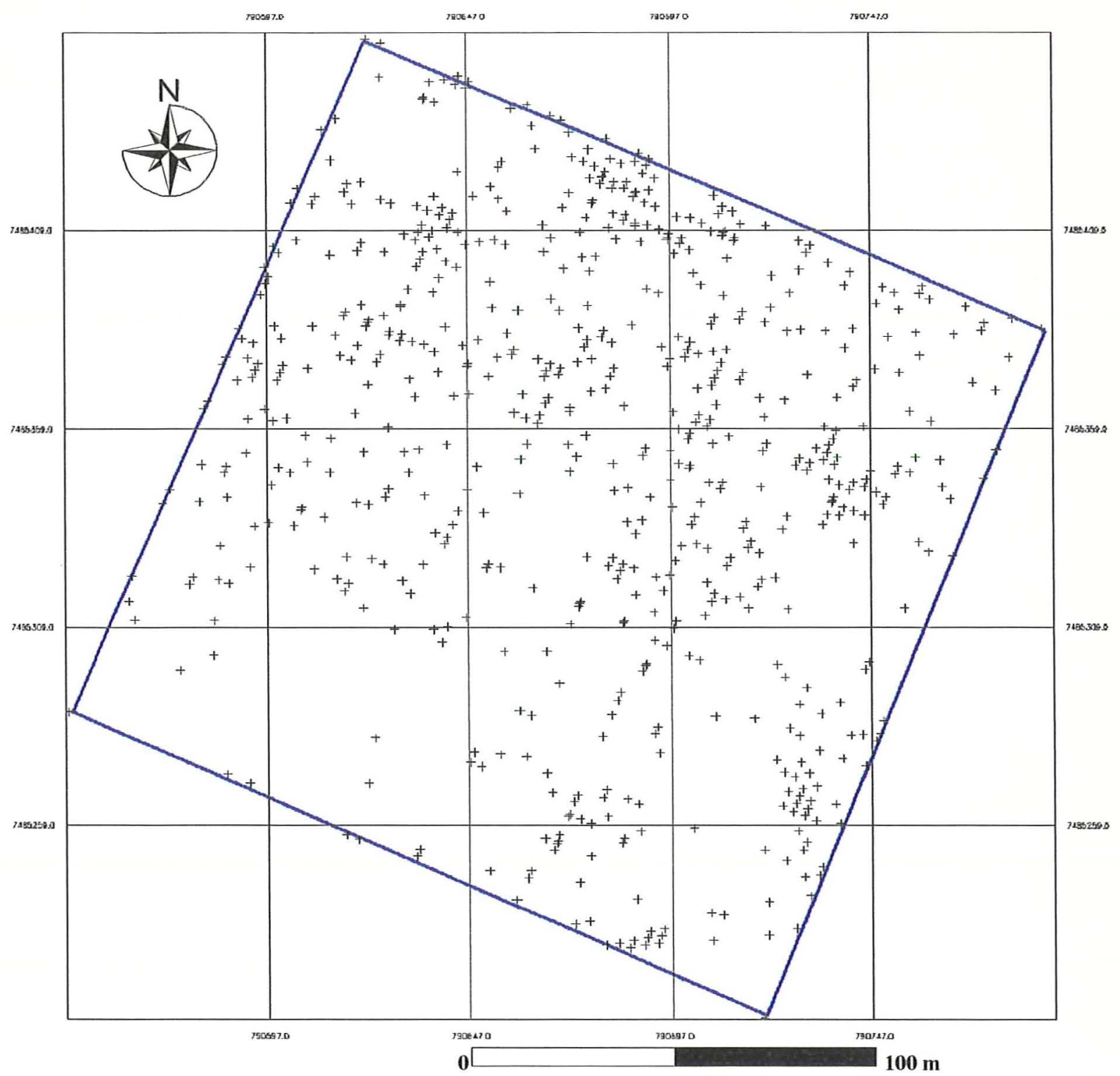

Figura 8 - Distribuição das mudas atacadas por cupins na área 1:

- $\quad+$ : mudas atacadas. 


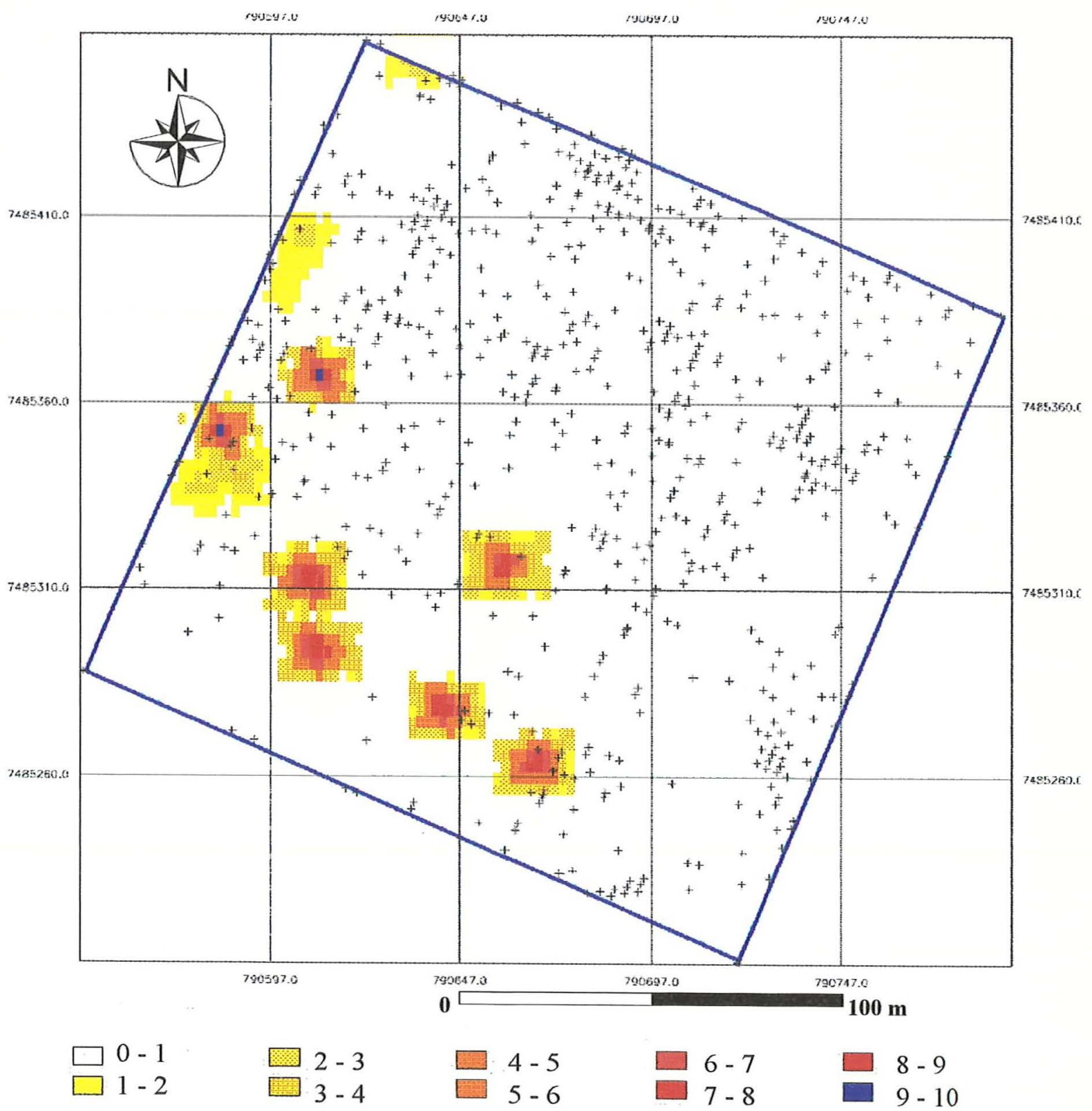

Figura 9 - Distribuição dos cupins na área 1 de acordo com as coletas nas iscas, sobreposta as mudas atacadas por cupins:

- cores: notas das iscas;

- +: mudas atacadas. 


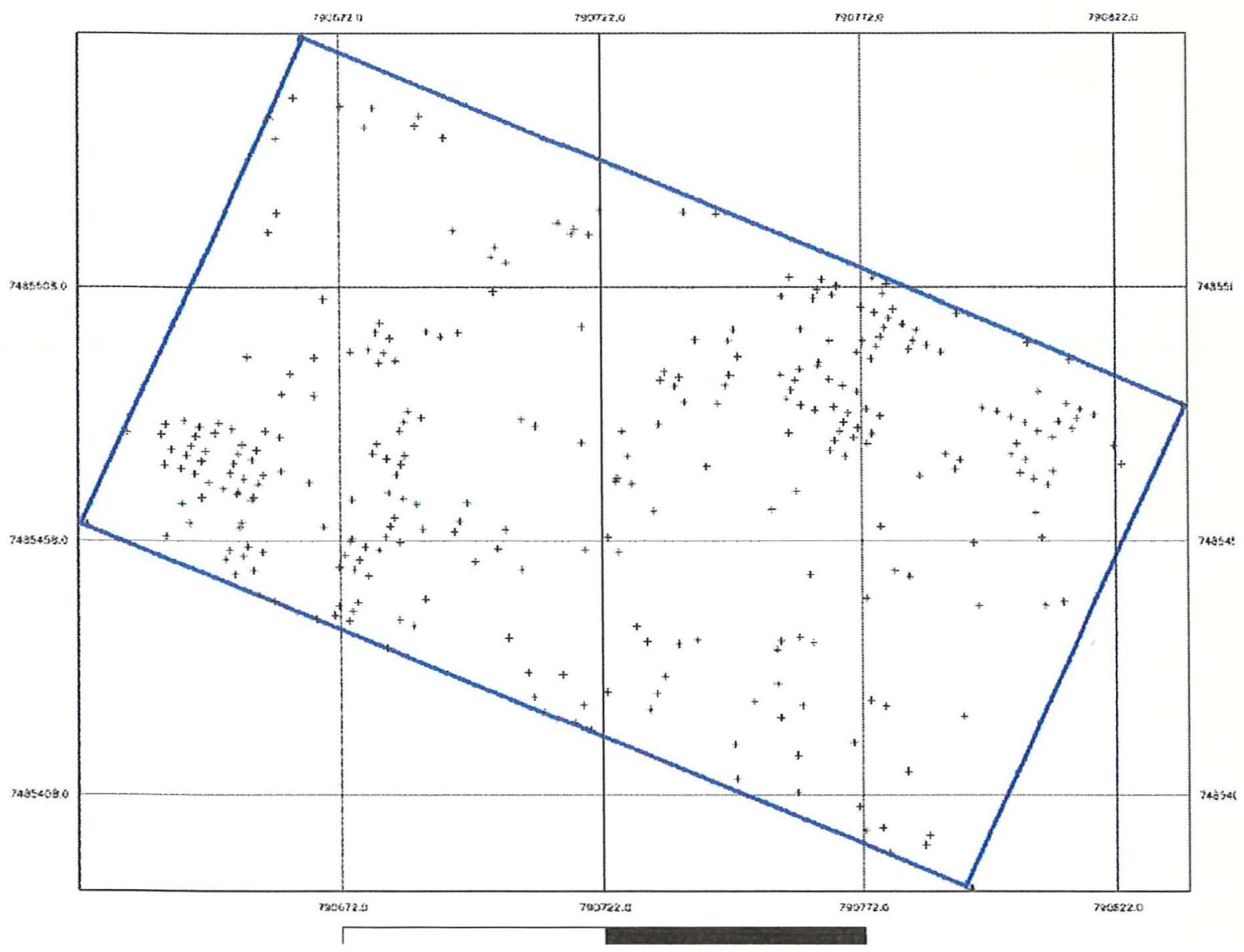

Figura 10 - Distribuição das mudas atacadas por cupins na área 2:

- +: mudas atacadas. 


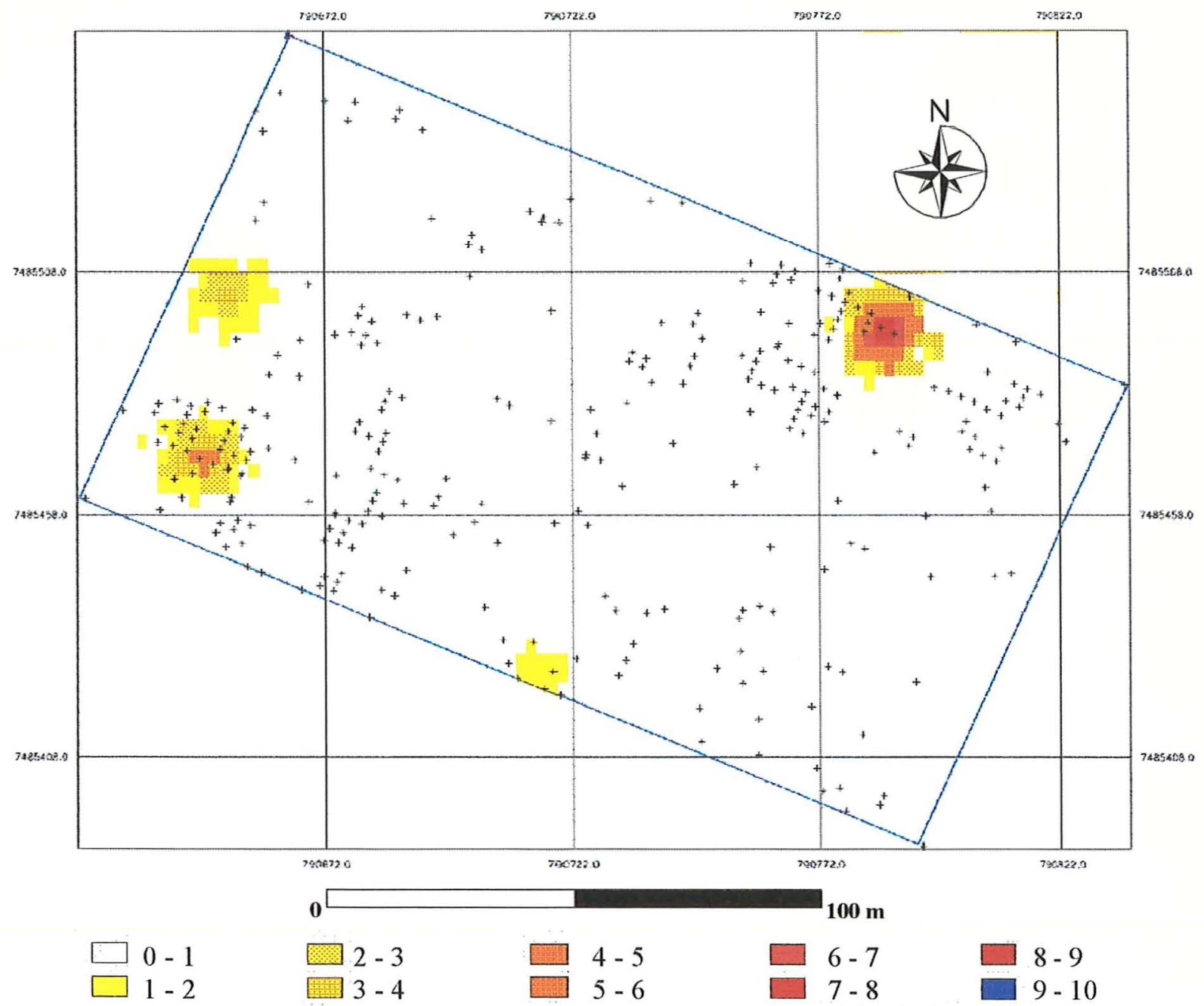

Figura 11 - Distribuição dos cupins na área 2 de acordo com as coletas nas iscas, sobreposta as mudas atacadas:

- cores: notas das iscas;

- $\quad+$ : mudas atacadas. 


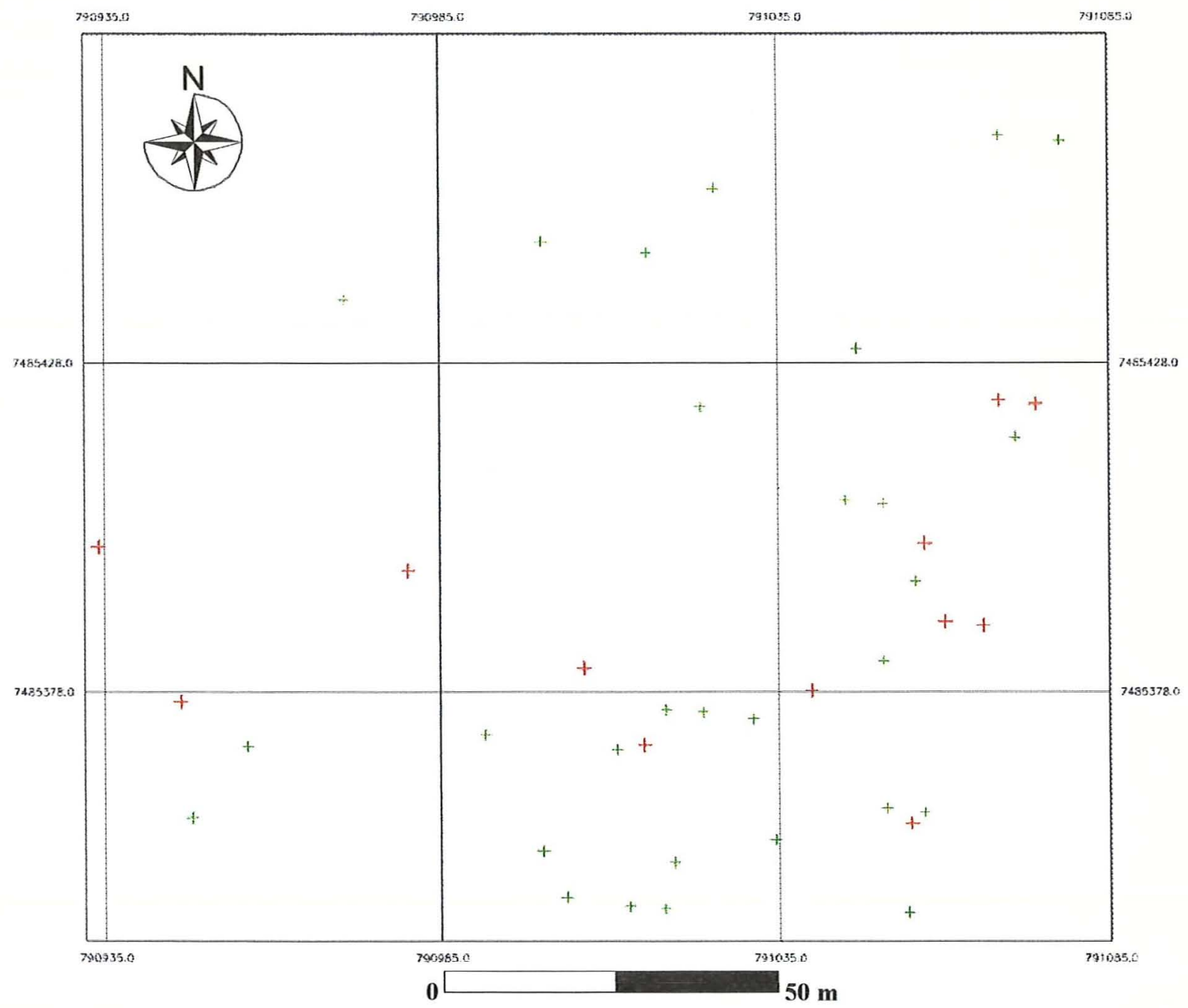

Figura 12 - Distribuição dos ninhos de montículos e das árvores que apresentaram cupins sob a casca na área 3:

- +: árvores de Eucalyptus com cupins sob a casca;

- +: ninhos de montículo. 


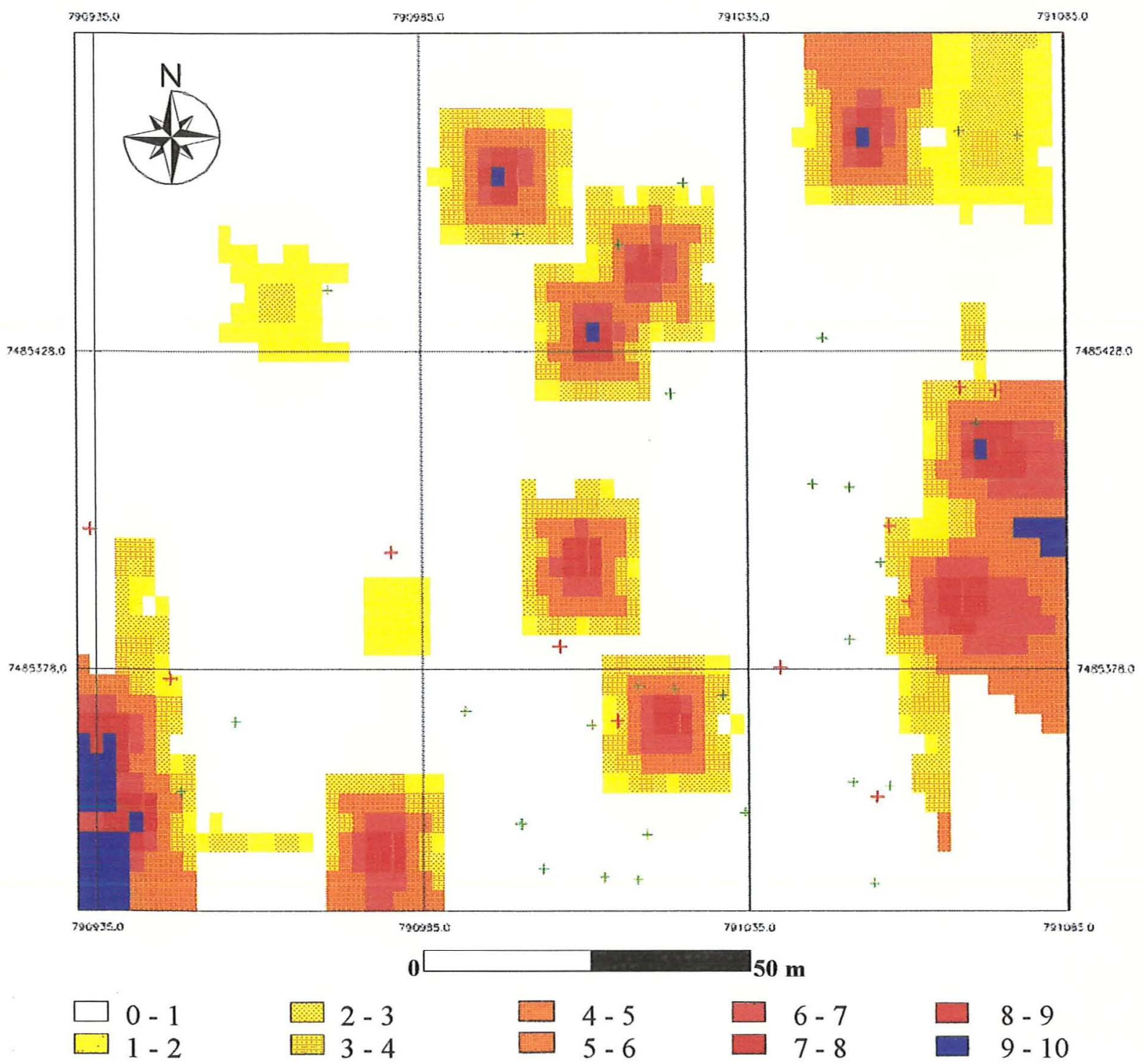

Figura 13 - Distribuição dos cupins na área 3 de acordo com as coletas nas iscas, sobreposta aos ninhos e cupins presentes sob a casca das árvores:

- cores: notas das iscas;

- +: árvores de Eucalyptus com cupim sob a casca;

- +: ninhos de montículo. 


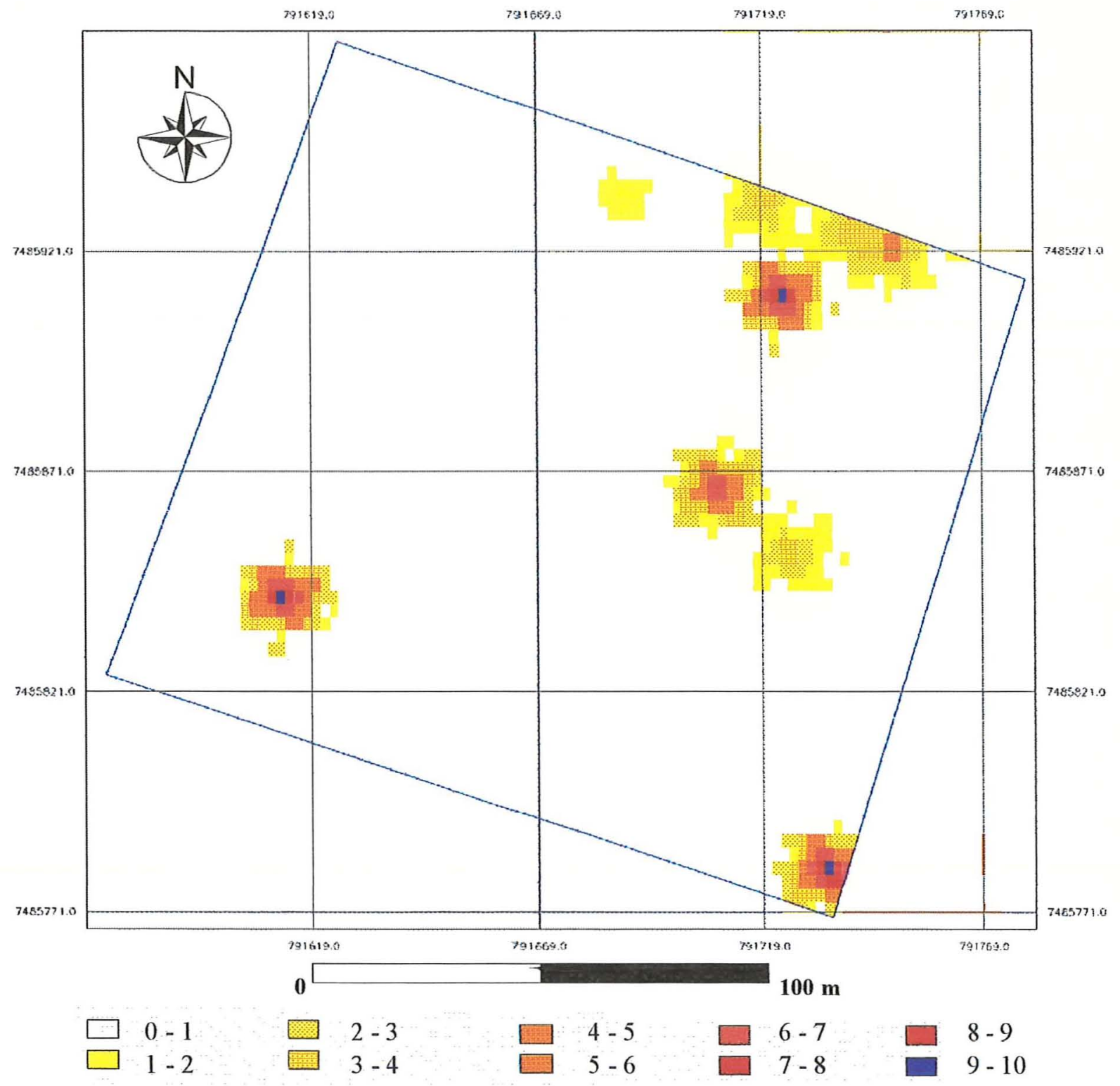

Figura 14 - Distribuição dos cupins na área 4 de acordo com as coletas nas iscas: - cores: notas das iscas. 


\subsection{Estatística}

De acordo com as freqüências observadas e esperadas da variável Ocorrência de Cupins nas Iscas nas áreas com E. saligna e E. urophylla x E. grandis, o valor de $\chi^{2}$ calculado foi igual 2,19, menor que o $\chi^{2}$ tabelado (igual a 3,84 ao nivel de $5 \%$ e 6,64 ao nível de $1 \%$ ), com 1 grau de liberdade. Portanto pelo teste de $\chi^{2}$ não se rejeita a hipótese de independência considerando-se um nível mínimo de significância de $5 \%$, isto é, a ocorrência de cupins nas iscas é independente das áreas de Eucalyptus (Tabela 8 e Figura 15).

Tabela 8. Freqüências observadas e esperadas para a Ocorrência de Cupins nas Iscas por áreas com Eucalyptus saligna e E. urophylla $x$ E. grandis.

\begin{tabular}{|c|c|c|c|}
\hline & & & \\
\hline CUPINS & E. saligna & E. urophylla $\times$ E. grandis & Total \\
\hline $\begin{array}{c}\text { Ocorreram } \\
\text { Năo Ocorreram }\end{array}$ & $\begin{array}{c}18(14,65) \\
401(404,35)\end{array}$ & $\begin{array}{c}5(8,35) \\
234(230,65) \\
\end{array}$ & $\begin{array}{l}23 \\
635 \\
\end{array}$ \\
\hline Total & 419 & 239 & 658 \\
\hline
\end{tabular}

Para as freqüências observadas e esperadas da variável Mortalidade das Mudas Infestadas nas áreas com E. saligna e $E$. urophylla $\times E$. grandis, o valor de $\chi^{2}$ calculado foi igual a 8,35, maior que o $\chi^{2}$ tabelado ao nivel de $1 \%(6,64)$, com 1 grau de liberdade. Portanto pelo teste de $\chi^{2}$ rejeita-se a hipótese de independência ao nível de $1 \%$ de significância, isto é, a morte das mudas infestadas depende das áreas de Eucalyptus (Tabela 9 e Figura 16).

Tabela 9. Freqüências observadas e esperadas para Mortalidade das Mudas Infestadas nas áreas com $E$. saligna e $E$. urophylla $\times E$. grandis.

\begin{tabular}{|c|c|c|c|}
\hline & & & \\
\hline MUDAS & E. saligna & E. urophylla $\times$ E. grandis & Total \\
\hline Morreram & $656(615,51)$ & $300(340,49)$ & 956 \\
\hline Não Morreram & $5266(5306.49)$ & $2976(2935,51)$ & 8242 \\
\hline Total & 5922 & 3276 & 9198 \\
\hline
\end{tabular}

Quando consideradas as freqüências observadas da variável Freqüência de Cupins por Espécies nas áreas com E. saligna e E. urophylla $\times$ E. grandis, dado que a espécie Heterotermes tenius apresentou ocorrência $>1000$, para as duas áreas, retirouse essa espécie para aplicação do teste de $\chi^{2}$. Como se tinha o valor exato de ocorrência e sabendo-se que foi igual para ambas as áreas, sua exclusão não influiria no resultado do teste (Tabela 10). 
Tabela 10. Freqüências observadas para Freqüência de Cupins por Espécies nas áreas com Eucalyptus saligna e E. urophylla $\times E$. grandis.

\begin{tabular}{|c|c|c|c|}
\hline \multirow[b]{2}{*}{ ESPÉCIES } & \multicolumn{2}{|c|}{ AREAS } & \multirow[b]{2}{*}{ Total } \\
\hline & E. saligna & E. urophylla $\times E$. grandis & \\
\hline Embiratermes sp. & 19 & 0 & 19 \\
\hline $\begin{array}{l}\text { Comitermes sp. } \\
\text { Heterotermes tenuis }\end{array}$ & 176 & 0 & 176 \\
\hline Heterotermes tenuis & $>1000$ & $>1000$ & $>1000$ \\
\hline $\begin{array}{l}\text { Apicotermitinae } \\
\text { Comitermes cumulans }\end{array}$ & $\begin{array}{l}0 \\
0\end{array}$ & $\begin{array}{l}41 \\
52\end{array}$ & $\begin{array}{l}41 \\
52\end{array}$ \\
\hline Total & $>1000$ & $>1000$ & $>1000$ \\
\hline
\end{tabular}

Nas freqüências observadas e esperadas para os resultados sem a espécie Heterotermes tenuis, o valor de $\chi^{2}$ calculado foi 288 , maior que $\circ \chi^{2}$ tabelado ao nivel de $1 \%(11,35)$, com 3 graus de liberdade. Portanto pelo teste de $\chi^{2}$ rejeita-se a hipótese de independência ao nível de $1 \%$ de significância, isto é, o número de cupins por espécie é dependente das áreas de Eucalyptus (Tabela 11).

Tabela 11. Freqüências observadas e esperadas para Freqüência de Cupins por Espécies nas áreas com Eucalyptus. saligna e E. urophylla $\times$ E. grandis.

\begin{tabular}{|c|c|c|c|}
\hline \multirow[b]{2}{*}{ ESPÉCIES } & \multicolumn{2}{|c|}{ ÁREAS } & \multirow[b]{2}{*}{ Total } \\
\hline & E. saligna & E. urophylla $\times$ E. grandis & \\
\hline $\begin{array}{l}\text { Embiratermes sp. } \\
\text { Comitermes sp. } \\
\text { Apicotermitinae } \\
\text { C. cumulans }\end{array}$ & $\begin{array}{c}19(12,86) \\
176(119,17) \\
0(27,76) \\
0(35,21)\end{array}$ & $\begin{array}{c}O(6,14) \\
O(56,86) \\
41(13,24) \\
52(16,79)\end{array}$ & $\begin{array}{c}19 \\
176 \\
41 \\
52\end{array}$ \\
\hline Total & 195 & 93 & 288 \\
\hline
\end{tabular}

Observe-se que o ponto de inércia do $\chi^{2}$, nesse caso, é igual a 1 , ou seja, a relação entre as duas variáveis é notoriamente de dependência, pois duas espécies de cupins, Embiratermes sp. e Comitermes sp., apareceram apenas na área com $E$. saligna, e enquanto que uma espécie Apicotermitinae e $C$. cumulans somente na área com E. urophylla $\times$ E. grandis (Figura 17). 


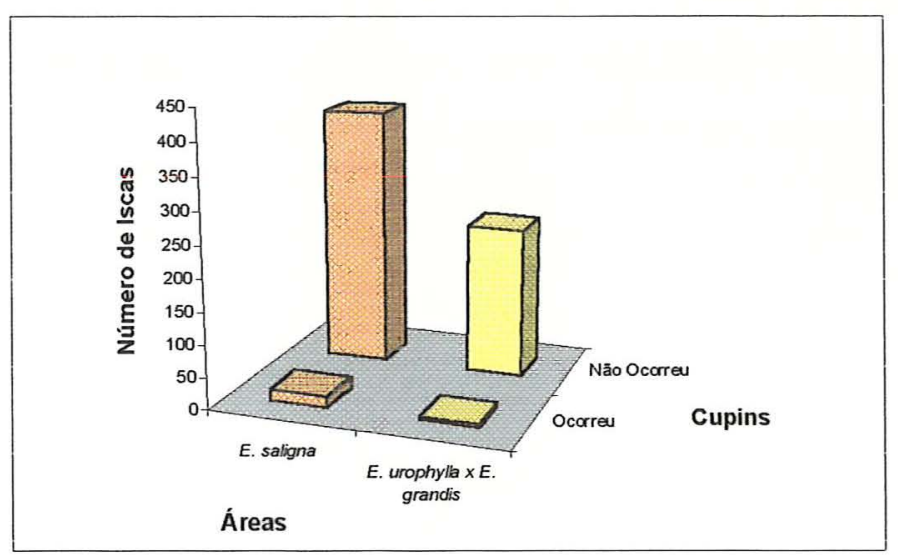

Figura 15 - Ocorrência de cupins nas iscas nas áreas com E. saligna e E. urophylla $x$ E. grandis.

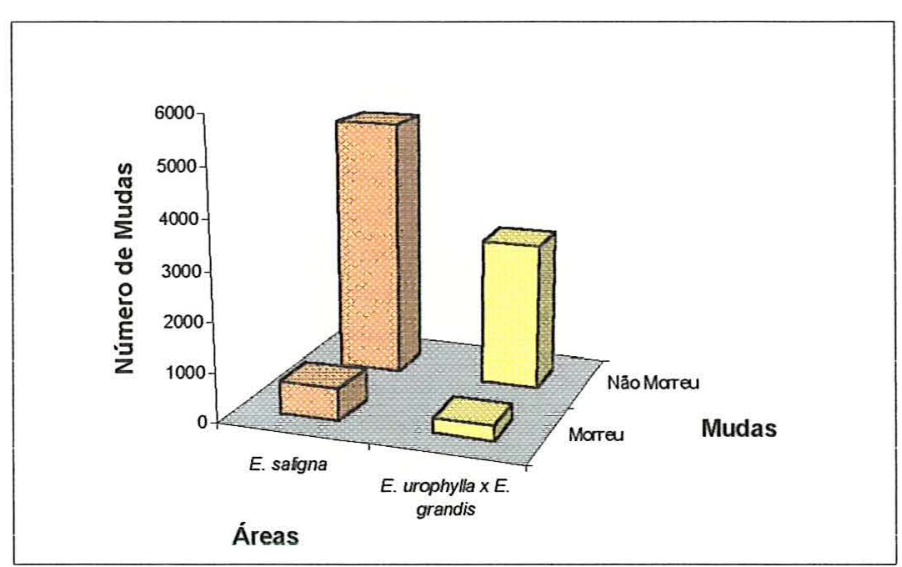

Figura 16- Mortalidade das mudas infestadas nas áreas com $E$. saligna e $E$. urophylla $\times$ E. grandis.

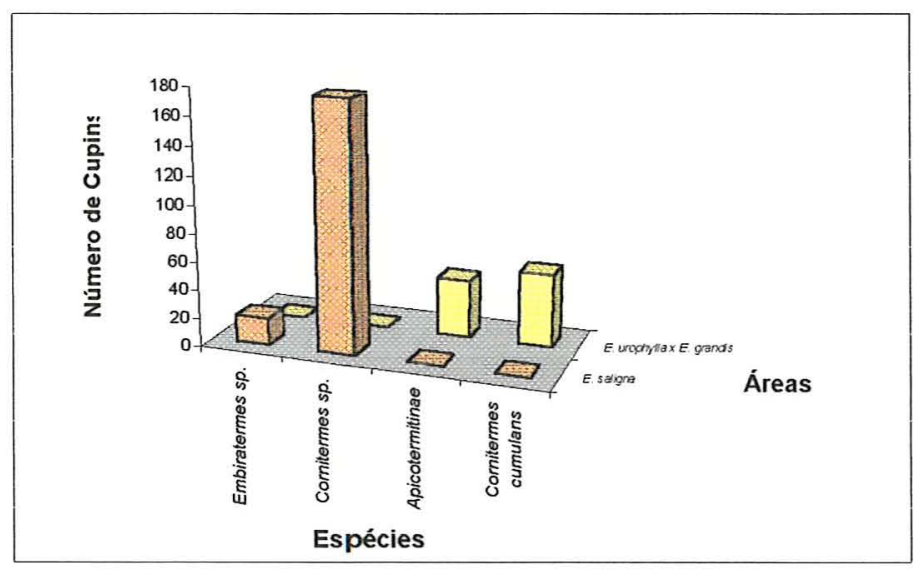

Figura 17 - Cupins por espécies nas áreas com E. saligna e E. urophylla x E. grandis. 
Pelos resultados apresentados, pode-se inferir que a ocorrência de cupins nas iscas não diferiu entre as espécies de Eucalyptus, porém, a mortalidade de mudas devido ao ataque por cupins foi maior em $E$. saligna. Observou-se também diferença significativa entre espécies de cupins nas áreas. A área 1, com $E$. saligna apresentou Embiratermes sp. e Comitermes sp. e a área 2, com E. urophylla $\times$ E. grandis apresentou uma espécie de Apicotermitinae e a espécie C. cumulans. Já a espécie Heterotermes tenuis apareceu em número igual nas duas áreas de Eucalyptus.

Quando comparada a presença de cupins nas iscas nas quatro áreas estudadas, pode-se observar que nas áreas 3 e 4, também houve ocorrência de espécies diferentes (Figura 18). 

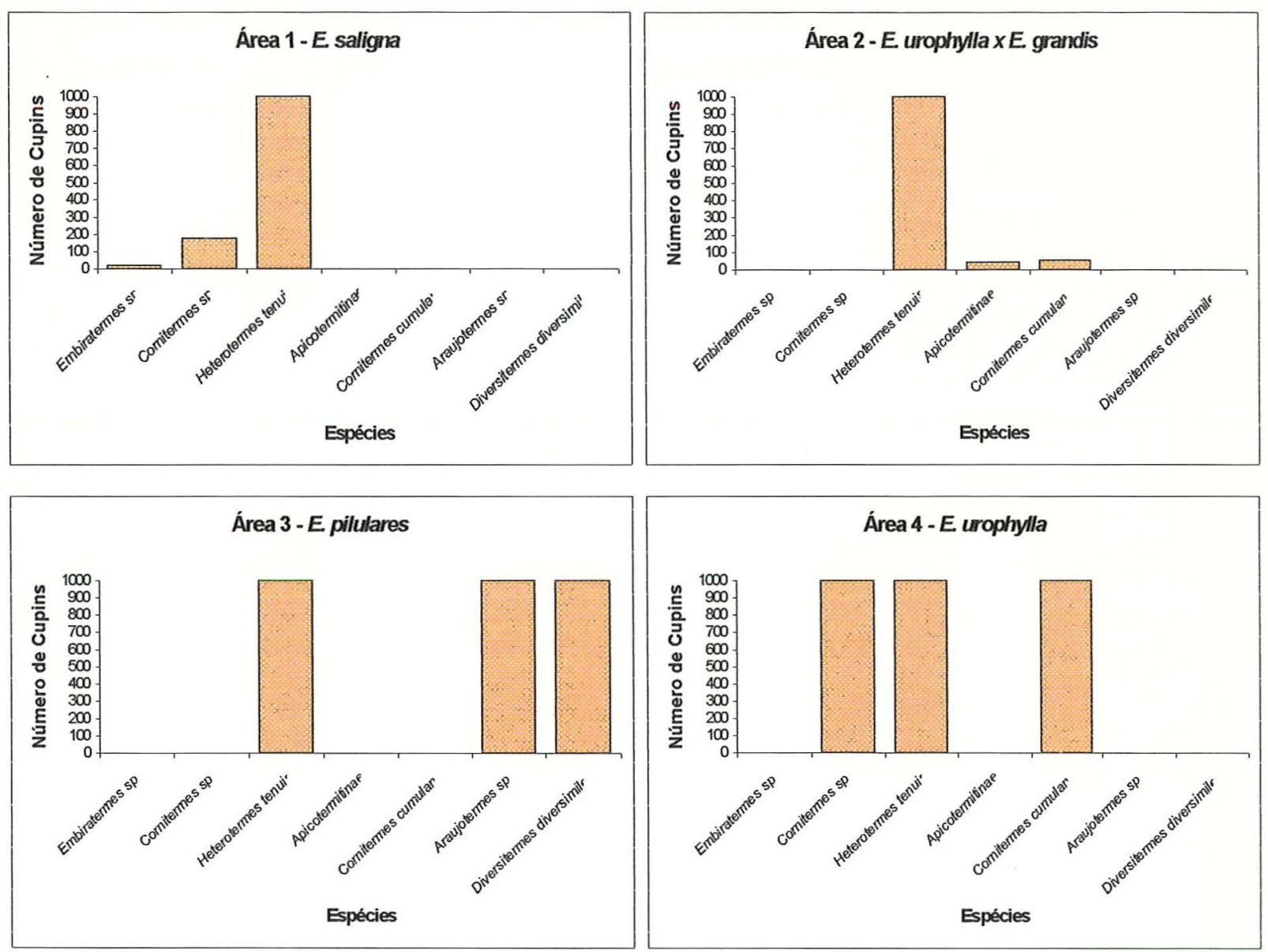

Figura 18 - Freqüência de cupins por espécies nas quatro áreas avaliadas. 
De acordo com Wilcken \& Raetano (1998), o gênero Embiratermes está referido para Eucalyptus grandis e hibridos, atacando raízes de mudas. O gênero Cornitermes é citado para Eucalyptus spp. (raizes das plantas adultas) e para $E$. grandis e $E$. citriodora (raizes de mudas). A espécie C. cumulans é citada em Eucalyptus spp. atacando as raizes das plantas adultas. Para $C$. bequaerti é citado ataque às raízes e colo de mudas de $E$. urophylla e, $H$. tenuis, aparece causando danos no tronco de Eucalyptus spp. Da subfamilia Apicotermitinae, os autores verificaram ataque às raizes de Eucalyptus spp. por Anoplotermes sp. e A. pacificus.

Assim, a maioria das espécies coletadas teria potencial para provocar o dano verificado nas áreas, porém somente $H$. tenuis apresentou grande densidade populacional nas iscas (>1.000 indivíduos), além de ser a única espécie em comum nas áreas 1 e 2, com alto percentual de perda de mudas devido aos cupins, sugerindose que esta espécie esteja associada a mortalidade verificada. No Brasil, danos por Heterotermes, são relatados em diversas culturas agrícolas (Almeida et al., 1984; Pizano \& Fontes, 1986; Domingos et al., 1988; Almeida \& Alves, 1995; Alves \& Almeida, 1995; Campos et al., 1998).

Nas avaliações das mudas mortas por cupins nas áreas 1 e 2, foi possível perceber destruição do sistema radicular da muda, causando grandes falhas no plantio. O replantio foi necessário nestas áreas, mas não evitou a desuniformização.

Almeida et al. (1984), estudando a ocorrência de cupins dos gêneros Heterotermes, Coptotermes e Cornitermes em tocos de seringueira no estado do Pará, relataram que o ponto usual de invasão é na parte terminal da raiz principal, podendo ocorrer em outros pontos da mesma maneira. $O$ ataque concentra-se a uma profundidade de $20 \mathrm{~cm}$ do solo e todo o sistema radicular pode ser destruído, eliminando as plantas do campo, desuniformizando a plantação, tornando necessário o replantio.

Neste trabalho, optou-se pelo uso das iscas Termitrap $^{\circledR}$, que têm sido utilizadas com sucesso para atrair cupins $H$. tenuis em cana-de-açúcar, com a finalidade de localização de focos, monitoramento e controle desta importante praga de canaviais (Almeida \& Alves, 1995; Alves \& Almeida, 1995; Campos et al., 1998). 
Para Sands (1972) as iscas são uma alternativa na coleta e estudo de cupins subterrâneos, que por estarem sob o solo, em ninhos difusos, sem indicativos de sua presença na superfície, são de dificil detecção.

Colocadas diretamente no solo, as iscas podem ser de estrume bovinotpapel; colmo de milho; pedaços de madeira (estacas, blocos ou placas) livres ou dentro de recipientes perfurados; papel higiênico livre ou dentro de tambores perfurados $e$ papelão corrugado livre ou em dentro de tubos de PVC. A coleta por iscas, além de ser um método rápido e econômico, facilita a amostragem em grandes áreas, minimiza o erro do coletor e permite comparação dos dados (Costa-Leonardo, 1997).

De acordo com o mesmo autor, ainda existe muita polêmica quanto a melhor metodologia para amostragem e coleta de cupins subterrâneos e, para a escolha da técnica mais adequada, vários fatores devem ser considerados, como perfil da área amostrada (dimensão, vegetação, tipo de solo, clima, etc) e espécies de cupins presentes no local, pois iscas utilizadas em certos ambientes, podem não ser funcionais em outros.

A baixa freqüência de consumo de iscas em todas as áreas, não exclui que outras espécies de cupins possam existir no local. Os reflorestamentos, diferentes das culturas agrícolas onde o solos são constantemente revolvidos, possuem cultivos com ciclos de sete anos em média, com grande quantidade de raízes, folhas, pedaços e cascas de madeira. Como este material compete com as iscas, provavelmente, o "acaso" seja o fator atuante na localização destas pelo cupim neste ecossistema.

Martius (1998), em revisão sobre controle biológico de cupins, cita que o feromônio de trilha, secretado pela glândula esternal e indutor do comportamento de seguimento, pode também ser emitido por fontes externas, como o fungo decompositor da madeira Gloeophyllum trabeum, que atrai Rhinotermitidae à madeira podre. Semioquímicos isolados de fungos de decomposição induzem os cupins a seguir uma trilha, agregar-se e alimentar-se.

A utilização do sistema GPS foi uma tentativa de obter dados sobre os locais de incidência de cupins no cultivo, uma vez que Forti \& Andrade (1995) evidenciaram que os cupins ocorrem em focos isolados porém não há dados sobre a distribuição espacial das colônias no campo, carecendo de dados específicos na literatura nacional. 
Nas áreas 1 e 2, como foi realizada contagem e localização das mudas mortas, esperar-se-ia que os locais de iscas com cupins, estivessem próximos ou sobrepostos aos locais de maior número de mudas mortas. Entretanto, quando estas informações foram cruzadas através do sistema Spring 3.3 , as duas regiões não coincidiram na grande maioria.

Vários fatores podem ter ocasionado esta diferença nos locais de ataque de mudas e iscas. Como o levantamento das mudas ocorreu após quatro meses de plantio e a colocação e a coleta com iscas ocorreu entre nove e doze meses após o plantio, quando os eucaliptos já estavam maiores e portanto não tão suscetiveis ao ataque, $O$ desencontro entre locais de mudas mortas e iscas atacadas poderia ser decorrente de uma mudança nos locais de forrageamento no espaço de tempo da obtenção dos dados.

Também devido ao intervalo de tempo entre as duas coletas, a hipótese do ataque às iscas estar concentrado em um dos lados do plantio, poderia indicar melhores condiçōes de umidade ou outras características edáficas típicas do solo daquele local. Além disso, a vegetação adjacente da área, pode ter influenciado na atividade dos cupins.

Em trabalho envolvendo a problemática dos cupins no estabelecimento de plantações de Eucalyptus na África, Wardell (1987) constatou que danos localizados, devido ao ataque por cupins, resultaram em $50-80 \%$ de mortalidade, com período crítico ocorrendo entre 4-6 meses de plantio. A grande variedade de cupins a a atividade sazonal destas nos sítios acentuaram os prejuizos.

Nair \& Varma (1985) sugerem que mais fatores estejam relacionados na interação eucalipto $x$ cupins, tais como espécies de cupins presentes, densidade populacional, ritmo sazonal de atividade, acúmulo de "litter" e madeira, condições do solo, estado fisiológico da planta, idade, estado de estabelecimento e espécies em questão.

Segundo Wardell (1987), muitas das questões referentes ao problema com cupins em Eucalyptus permanecem sem resposta, por falta de programas de pesquisa que estudem as relações ecológicas entre cupins e árvores hospedeiras e possiveis correlações com fatores edáficos. 
$\mathrm{Na}$ área 3, como não foi realizado levantamento de todas as árvores com cupins e de todos os ninhos de montículo, muitas vezes o local do transecto não coincidiu com o local da isca, logo a figura dos locais com cupins nas iscas também não sobrepôs alguns pontos de coleta manual de cupins.

A utilização de sistema GPS no mapeamento das mudas mortas, na localização espacial de ninhos e dos locais de atividade dos cupins em iscas no campo é bastante promissora, desde que realizada simultaneamente com a coleta de dados das mudas mortas. Um equipamento preciso, aliado aos programas de geoprocessamento, pode fornecer uma nova ferramentas de trabalho para o estudo de cupins, não só em floresta, mas em várias culturas.

A área 4 apresenta resultado interessante, onde a ausência de mudas atacadas, pelo menos na época de estudo, poderia ser explicada pela utilização do produto quimico deltametrina, em calda emulsäo, para mergulhar os tubetes com as mudas antes do plantio. Porém, através da figura dos cupins encontrados em isca nesta área, foi possível verificar que o produto químico atuou apenas como um repelente, não controlando as populações, já que os cupins estavam presentes nas coletas.

De acordo com Wilcken \& Raetano (1998) está crescendo no Brasil o método de imersão de mudas em emulsões inseticidas no pré-plantio, com as vantagens de redução de custos, alto rendimento no tratamento das mudas e baixo tempo de imersão das mudas. Segundo os autores, a eficiência do controle fica entre 90 a $100 \%$ até seis meses após o plantio. Os principais problemas para este tratamento são os cuidados no ato do plantio, especialmente a profundidade da cova.

A ausência de mudas atacadas por cupins seria esperada, pois estaria ainda dentro do periodo de seis meses de eficiência do inseticida. Entretanto, as espécies de cupins encontradas nesta área, têm potencial para causar danos nas mudas, após os seis meses, havendo necessidade de monitoramento do local e medidas preventivas de controle.

Por fim, apesar dos cupins imporem prejuizos a algumas fases do processo de reflorestamento, deve-se ressaltar que a diversidade total de cupins, tem papel benéfico no ambiente, pois, de acordo com Berti Filho (1995), participam na 
decomposição de matéria orgânica, na ciclagem de nutrientes, na aeração e drenagem de solos.

Mando (1997a, 1997b) comprovou que a atividade dos cupins em solos compactados aumenta a porosidade do solo, beneficiando a infiltração, 0 armazenamento e a drenagem de água. $O$ autor ainda abordou a questão do manejo adequado dos cupins no solo e sua atuação sobre a vegetação.

Um dos principais problemas relacionado aos danos de cupins em reflorestamentos refere-se justamente ao manejo do solo. Nair \& Varma (1985) sugerem justamente que a preparação do solo para o plantio de eucaliptos, com a retirada da vegetação e ausência de "litter", ocasionaria o ataque ao eucalipto, já que os ninhos subterrâneos não sofreram danos e os cupins estariam privados de sua alimentação normal.

O estudo de cupins em florestas ainda é insipiente e carece de informações para a realização de manejo e controle adequados desta fauna. Conhecendo a diversidade total de espécies presentes nos plantios e sua distribuição espacial, podese avaliar o potencial destas espécies tornarem-se pragas, bem como os locais prováveis de ataque.

Com estas informações, tem-se subsídios para realizar uma avaliação adequada do problema, já que, de acordo com Martius (1998) para o controle, exige-se que seja feita uma análise do balanço entre o beneficio esperado pela eliminação de cupins e os possíveis efeitos da eliminação de partes da fauna do solo, que tem importante papel na ciclagem de nutrientes, sendo necessários estudos específicos para cada situação. 


\section{CONCLUSÕES}

- As iscas de papelão não têm a mesma eficiência que se verifica nas áreas agricolas, porque nos solos de reflorestamento ocorrem raizes, cascas, restos de madeiras, etc, que são muito mais atrativos para os cupins;

- mudas reconhecidamente tratadas com deltametrina no pré-plantio foram repelentes aos cupins, entretanto, observou-se que eles estavam presentes na área;

- o mapeamento da distribuição espacial dos cupins, através do sistema GPS de alta precisão, é uma ferramenta promissora para novos estudos, se aliada a programas geoprocessamento e Sistemas de Informações Geográficas;

- a interferência dos cupins na vegetação é pouco conhecida e os danos causados podem ser decorrentes do manejo inadequado do solo durante o processo de reflorestamento;

- novos estudos devem ser realizados em florestas comerciais de eucalipto, visando conhecer, de forma mais significativa, a atuação dos cupins neste ecossistema. 


\section{REFERÊNCIAS BIBLIOGRÁFICAS}

ALMEIDA, J.E.M.; ALVES, S.B. Seleção de armadilhas para captura de Heterotermes tenuis (Hagen). An. Soc. Entomol. Brasil, n.24, v.3, p.619-624, 1995.

ALMEIDA, M.M.B.; CALIL, A.C.P.; RODRIGUES, M.G. Constatação da ocorrência de cupins dos gêneros Heterotermes, Coptotermes e Comitermes em tocos de seringueira (Hevea spp.) no estado do Pará. In: $1^{\circ}$ Simpósio do Trópico Úmido, Belém, 1984. Anais. Belém: Embrapa, 1984. p.133-141.

ALVES, S.B.; ALMEIDA, J.E.M. Novas alternativas para o controle microbiológico de cupins. In: BERTI FILHO, E.; FONTES, L.R. (Ed.). Alguns aspectos atuais da biologia e controle de cupins. Piracicaba: FEALQ, 1995. p.95-102.

ANDERSEN, E.B. The Statistical Analysis of Categorical Data. $2^{\mathrm{a}}$ ed. Copenhagen, 1991. 532p.

ARAÚJO, R.L. Catálago dos Isoptera do Novo Mundo. Rio de Janeiro: Academia Brasileira de Ciências, Rio de Janeiro, 1977. 92p.

BERTI FILHO, E. Cupins ou térmitas. In: Manual de pragas em florestas, vol.3. Programa Cooperativo de Monitoramento de Insetos em Florestas - IPEF/SIF. 1993. $56 \mathrm{p}$.

BERTI FILHO, E. Cupins em florestas. In: BERTI FILHO, E.; FONTES, L.R. (Ed.). Alguns aspectos atuais da biologia e controle de cupins. Piracicaba: FEALQ, 1995. p.127-140.

BURT, C. The Factorial Analysis of Qualitative Data. British Journal of Psychology, Leicester, England, n.3, p.166-185, 1950.

CAMPOS, M.B.S.; ALVES, S.B.; MACEDO, N. Seleção de iscas celulósicas para o cupim Heterotermes tenuis (Isoptera: Rhinotermitidae) em cultura de cana-deaçúcar. Sci. agric. Piracicaba, n.55, v.3, p.480-484, 1998.

COATON, W.G.H. Report on investigation of the termite problems in potential plantations in Northern Rhodesia. Unpubl. Rep. Plant. Pretoria: Protection Institute, Division of Entomology, 1957. 127p. 
COSTA-LEONARDO, A.M. Métodos para coleta e estudo das populações de cupins subterrâneos. Naturalia, v.22, p.199-206, 1997.

COWIE, R.H.; LOGAN, J.W.M.; WOOD, T.G. Termite (Isoptera) damage and control in tropical forestry with special reference to Africa and Indo-Malasya: a rewiew. Bulletin of Entomological Research, v.79, p.173-184, 1989.

DIEHL-FLEIG, E.; FORTES, R.C.; SILVA, M.E. O problema de cupins no Rio Grande do Sul. In: BERTI FILHO, E.; FONTES, L.R. (Ed.). Alguns aspectos atuais da biologia e controle de cupins. Piracicaba: FEALQ, 1995. p.11-17.

DIETRICH, C.R.R.C. Ocorrência de cupins (Insecta: Isoptera) em reflorestamento de Eucalyptus spp. Piracicaba, 1989. Dissertação (M.S) - Escola Superior de Agricultura "Luiz de Queiroz", Universidade de São Paulo.

DOMINGOS, D.J.; GONTIJO,T.A.; CAVENAGHI, T.M.C.M. Uso diferencial de madeiras por térmitas em cerrado. Brasil Florestal, n.66, p.26-31, 1988.

FERNANDES, P.M.; CZEPAK, C.; VELOSO, V.R.S. Cupins de montículos em pastagens: prejuizo real ou praga estética? In: FONTES, L.R.; BERTI FILHO, E. (Ed.).Cupins. O desafio do conhecimento. Piracicaba: FEALQ, 1998. p.187-210.

FONTES, L.R. Acréscimos e correções ao "Catálago dos Isoptera do Novo Mundo". Rev. Bras. Entom, v.17, n.2, p.137-145, 1983.

FONTES, L.R. Sistemática geral de cupins. In: BERTI FILHO, E.; FONTES, L.R. (Ed.). Alguns aspectos atuais da biologia e controle de cupins. Piracicaba: FEALQ, 1995. p.11-17.

FORTI, L.C., ANDRADE, M.L. Populações de cupins. In: BERTI FILHO, E.; FONTES, L.R. (Ed.). Alguns aspectos atuais da biologia e controle de cupins. Piracicaba: FEALQ, 1995. p.11-17.

GREENACRE, M.J. Correspondence Analysis in Pratice. London, Academic Press, 1993. 193p.

HARRIS, W.V. The role of termites in tropical forestry. Insectes Sociaux. v.XIII, n.4, p.255-266, 1966.

HARRIS, W.V. Termites: their recognition and control. 2 ed. Londre: Longman, 1971.186p.

MANDO, A. Effect of termites and mulch on the physical rehabilitation of structurally crustred soils in the sahel. Land degradation \& Development, v.8, p.269-278, 1997a.

MANDO, A. The impact of termites and mulch on the water balance of crustred Sahelian soil. Soil Technology, v.11, p.121-138, $1997 b$. 
MARICONI, F.A.M.; PASSOS, H.R.; GALAN, V.B.; ROCHA, M.T.; SILVA, R.A.A. Novidades no controle do cupim-de-monte Cornitermes cumulans (Kollar, 1832) . In: BERTI FILHO, E.; FONTES, L.R. (Ed.). Alguns aspectos atuais da biologia e controle de cupins. Piracicaba: FEALQ, 1995. p.85-88.

MARTIUS, C. Perspectivas do controle biológico de cupins (Insecta, Isoptera). Revta Bras. Ent, v.41, n.2-4, p.179-194, 1998.

NAIR, K.S.S.; VARMA, R.V. Some ecological aspects of the termite problem in young eucalypt plantations in Kerala, India. Forest Ecology and Management, V.12, p. 287-303, 1985.

PIMENTEL, D. Species diversity and insect population outbreaks. Annals of the Entomological Society of America, v.54, p.76-86, 1961.

PIZANO, M.A.; FONTES, L.R. Ocorrência de Heterotermes tenuis (Hagen, 1858) e Heterotermes longiceps (Snyder, 1924)(Isoptera: Rhinotermitidae) atacando canade-açúcar no Brasil. Brasil Açucareiro, v.104, n.3/4, p.29, 1986.

SANDS, W.A. Problems in attempting to sample tropical subterranean termite populations. Ekologia Polska, v.XX, n.3, p.23-31, 1972.

SANTOS, G.P.; ZANUNCIO, J.C.; ANJOS, N.; ZANUNCIO, T.V. Danos em povoamentos de Eucalyptus grandis pelo cupim de cerne Coptotermes testaceus Linnée, 1785 (Isoptera: Rhinotermitidae). Rev. Árvore, v.14, n.2, p. 155-163, 1990.

SELANDER, J.; BUDALA, M. A suvey of pest insects in forest research, Zambia. Research Note, n.33, 33p. 1983.

WARDELL, D.A. Control of termites in nurseries and young plantations in Africa: established practices and altemative courses of action. Commonw. For. Rev., v.66, n.1, p.77-89, 1987.

WILCKEN, C.F. Danos de cupins subterrâneos Comitermes sp. (Isoptera: Termitidae) em plantios de Eucalyptos grandis e controle com inseticidas no solo. Annais Soc. Entomol., v.21, n.3, p.329-338, 1992.

WILCKEN, C.F;; RAETANO, C.G. Controle de cupins em florestas. In: BERTI FILHO, E.; FONTES, L.R. (Ed.). Alguns aspectos atuais da biologia e controle de cupins. Piracicaba: FEALQ, 1995. p.141-154.

WILCKEN, C.F.; RAETANO, C.G. Atualidades no controle de cupins em florestas de eucalipto. In: FONTES, L.R.; BERTI FILHO, E. (Ed.).Cupins. O desafio do conhecimento. Piracicaba: FEALQ, 1998. p.173-185. 